\title{
Inverted porphyrins and expanded porphyrins: An overview
}

\author{
S K PUSHPAN, S VENKATRAMAN, V G ANAND, J SANKAR, H RATH \\ and T K CHANDRASHEKAR* \\ Department of Chemistry, Indian Institute of Technology, Kanpur 208016 , \\ India \\ e-mail: tkc@iitk.ac.in
}

\begin{abstract}
Porphyrins and metallopophyrins have attracted the attention of chemists for the past 100 years or more owing to their widespread involvement in biology. More recently, synthetic porphyrins and porphyrin-like macrocycles have attracted the attention of researchers due to their diverse applications as sensitizers for photodynamic therapy, MRI contrasting agents, and complexing agents for larger metal ions and also for their anion binding abilities. The number of $\pi$-electrons in the porphyrin ring can be increased either by increasing the number of conjugated double bonds between the pyrrole rings or by increasing the number of heterocyclic rings. Thus, $22 \pi$ sapphyrins, $26 \pi$ rubyrins, $30 \pi$ heptaphyrins, $34 \pi$ octaphyrins and higher cyclic polypyrrole analogues containing $40 \pi, 48 \pi, 64 \pi, 80 \pi$ and $96 \pi$ systems have recently been reported in the literature. These macrocycles show rich structural diversity where normal and different kinds of inverted structures have been identified. In this review, an attempt has been made to collect the literature of the inverted porphyrins and expanded porphyrins reported until December 2001. Since the meso aryl expanded porphyrins have tendency to form both inverted and non-inverted structures more emphasis has been given to meso aryl expanded porphyrins.
\end{abstract}

Keywords. Inverted porphyrins; N-confused porphyrins; rubyrins; heptaphyrins; octaphyrins.

\section{Introduction}

Porphyrins are the most widespread of all prosthetic groups found in nature ${ }^{1,2}$. These highly colored tetrapyrrolic pigments play such a diverse and critical role in nature ranging from electron transfer, oxygen transport, photosynthetic processes and catalytic substrate oxidation that they are aptly termed as 'pigments of life ${ }^{3}$. Porphyrins are $22 \pi$ electron systems whose main conjugation pathway contains $18 \pi$ electrons, which explains the aromatic nature from which the intense colour associated with them stems. The parent form of these tetrapyrrolic macrocycles has structure $\mathbf{1}$ known as porphine. The ubiquity of its functions in nature led researchers around the globe to focus their attention on these macrocycles and this paved the way to the syntheses of porphyrin-like macrocyclic units, that differed from the naturally occurring porphyrins and related systems in a number of ways, but mimicked their properties and functions outside biological systems.

The interdisciplinary interest generated by the porphyrins resulted in the syntheses of modified porphyrins (scheme 1) and the most important modifications are as follows: (a)

\footnotetext{
*For correspondence
} 


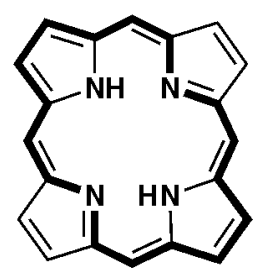

1

Periphery modified porphyrins - where the modifications are done on the periphery, which includes $\beta$ and meso positions of the parent tetrapyrrolic macrocycles; (b) Core modified porphyrins ${ }^{4}$ - where one or more core nitrogen atoms of parent porphyrin are substituted with chalcogen atoms; (c) Contracted porphyrins ${ }^{5}$ - obtained by removing one of the meso carbons resulting in the formation of corroles;-(d) Isomeric porphyrins ${ }^{6}$-structures which have same molecular formula $\mathrm{C}_{20} \mathrm{H}_{14} \mathrm{~N}_{4}$ obtained by scrambling the four pyrrolic subunits and the four bridging carbon atoms which are shown as structures 2-5; (e) Inverted porphyrins ${ }^{4}$ - which can also be considered porphyrin isomers which have one or more of the core nitrogens pointing out of the ring and hence and called ' $N$-confused porphyrins' or 'mutant porphyrins' and are treated as a different class (shown as structures 6 and 7); and (f) Expanded porphyrins ${ }^{7}-$ which result from the expansion of the $\pi$-electron conjugation by increasing the number of heterocyclic rings. The resulting chromophores show strong absorptions in the red region compared to those of normal $18 \pi$ porphyrins.

CONTRACTION INVERSION
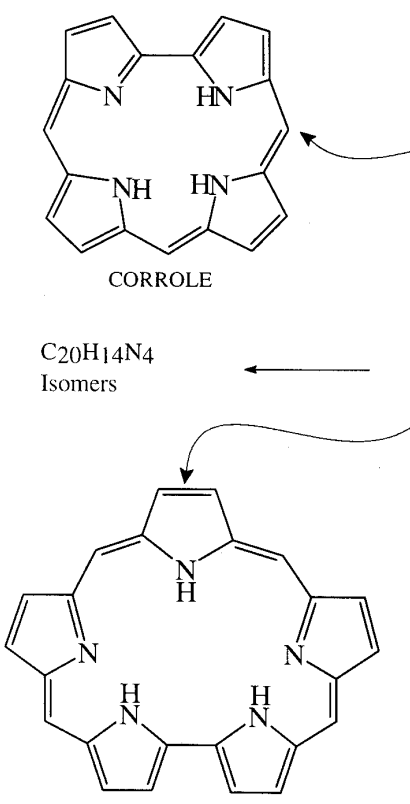

EXPANSION

CORE MODIFICATION

Scheme 1. 


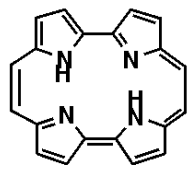

2

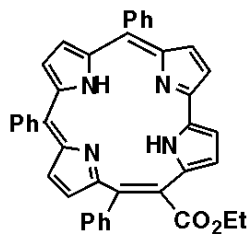

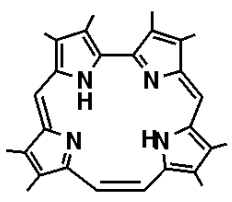

3

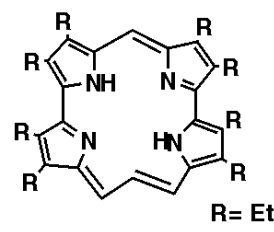

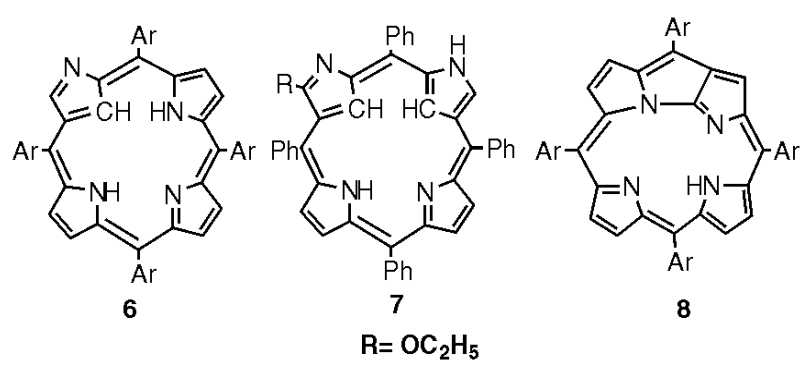

There are a variety of expanded porphyrins reported in the literature. They are sapphyrins $^{8}, \quad$ smaragdyrins $^{9}, \quad$ isosmaragdyrins ${ }^{10}$, pentaphyrins $^{11}$, hexaphyrins ${ }^{12}$, orangarins ${ }^{13}$, amethyrins ${ }^{13}$, octaphyrins ${ }^{14-16}$, rosarins ${ }^{17}$, rubyrins ${ }^{18}$, ozaphyrins ${ }^{19}$, bronzaphyrins $^{20,21}$, heptaphyrins ${ }^{22}$, turcasarins ${ }^{23}$, dodecaphyrins ${ }^{24}$, and hexadecaphyrins ${ }^{24}$. There are citations in the literature that these giant macrocycles can act as anionic, cationic and neutral complexing agents, which are substrate-specific and hence can be used in a variety of ways in medicine and industry ${ }^{7 a}$. Their photosensitizing ability to convert triplet oxygen to highly reactive and toxic singlet oxygen makes them indispensable in the field of photodynamic therapy ${ }^{25-27}$. The complexing ability to trap lanthanide metals make these macrocycles potent candidates as contrast agents in magnetic resonance imaging (MRI) ${ }^{28,29}$. Thus, these modifications result in the control of the electronic structure, and the geometry of the system and its surroundings, associated with rich, diverse and exotic chemistry.

These properties have generated considerable interest in synthesizing new macrocycles in high yields with different core atoms and cavity size that can reveal interesting spectroscopic, chemical and physical properties, which can find applications in biology ${ }^{30}$, medicine ${ }^{31}$, material science ${ }^{32}$ and catalysis ${ }^{33}$.

A brief survey of the earlier literature earlier in the field of porphyrin isomers and expanded porphyrin systems is given in the following sections.

\section{Porphyrin isomers}

Porphyrin isomers ${ }^{6}$, as the name indicates are tetrapyrrolic macrocycles, having a $\mathrm{C}_{20} \mathrm{H}_{14} \mathrm{~N}_{4}$ skeleton and $18 \pi$ electrons in the cyclic conjugated pathway. They are 
differentiated by the way the four-pyrrole units are interconnected. The first isomer of a porphyrin 'Porphycene' 2 [18] porphyrin-(2.0.2.0) was reported by Vogel's group in $1986^{34}$, followed by a gap of eight years in 1994, two more of its isomers 'corrphycene' 3 [18] porphyrin-(2.1.0.1) ${ }^{35}$, and 'hemiporphycene' 4 [18]porphyrin-(2.1.1.0) ${ }^{36}$ were reported. This period also marked the successful synthesis of $\mathrm{N}$-confused porphyrin (NCP) or inverted porphyrin 6 [18] porphyrin (1.1.1.1) $\left(\mathrm{C}_{\alpha}, \mathrm{N}, \mathrm{N}, \mathrm{N}\right)$ by two independent groups across the globe ${ }^{37}$. The fifth porphyrin isomer 'isoporphycene' 5 [18] porphyrin(3.0.1.0) was reported in $1996^{38}$. More recently Furuta and coworkers reported the synthesis of another isomer, 'doubly N-confused porphyrin' $\left(\mathrm{N}_{2} \mathrm{CP}\right) 7$ [18] porphyrin(1.1.1.1) $\left(\mathrm{C}_{\alpha}, \mathrm{C}_{\beta}, \mathrm{N}, \mathrm{N}\right)^{39}$ and ' $\mathrm{N}$-fused porphyrin' $\mathbf{8}^{40}$ derived from $\mathrm{N}$-confused porphyrin by appropriate synthetic modifications.

\section{Inverted porphyrins (NCP)}

Latos-Grazynski and coworkers reported inverted (mutant or N-confused or carba) porphyrin (NCP) 6 i.e. 2-aza-21-carba-tetraaryl porphyrin, by the Rothemund reaction between tolualdehyde 11 and pyrrole 9 in presence of $\mathrm{BF}_{3} \cdot \mathrm{Et}_{2} \mathrm{O}$ in $\mathrm{CH}_{2} \mathrm{Cl}_{2}$ followed by oxidation with chloranil in $4 \%$ yield $^{37 a}$. Simultaneously Furuta and coworkers also reported the formation of NCP in the reaction with pyrrole 9 and benzaldehyde 10, in presence of $t-\mathrm{BuOH} / \mathrm{CH}_{2} \mathrm{Cl}_{2}(1: 1)$ and conc. $\mathrm{HBr}$ (1equivalent), stirring in dark for two days, followed by oxidation with chloranil in $5-7 \%$ yields (scheme 2$)^{37 \mathrm{~b}}$.

The mechanism for formation of porphyrin and carba porphyrin macrocycle was suggested by Latos-Grazynski and coworkers that two helical conformations of tetrapyrromethane $\mathbf{1 2}$ differing only by the rotation of the terminal pyrrole moiety with respect to the $\mathrm{C}_{\alpha}-\mathrm{C}_{\text {meso }}$ bond during the porphyrinogen ring closure (scheme 3 ) ${ }^{37 \mathrm{a}}$.

Many research groups have recently synthesised N-confused porphyrins (NCP). Dolphin and coworkers prepared periphery modified NCP $\mathbf{1 5}$ by the acid catalysed condensation of modified dipyrromethane $\mathbf{1 3}$ and dipyrromethanedialdehyde ${ }^{41} \mathbf{1 4}$ while Chandrashekar and coworkers ${ }^{42}$ reported the formation of meso-tetraaryl NCP by oxidative coupling reaction of appropriate dipyrromethane 16 in presence of $0.1 \mathrm{eq} . \mathrm{p}$ $\mathrm{TsOH}$ (scheme 4). Recently Lindsey and coworkers ${ }^{43}$ reported the formation of NCP $\mathbf{1 7}$

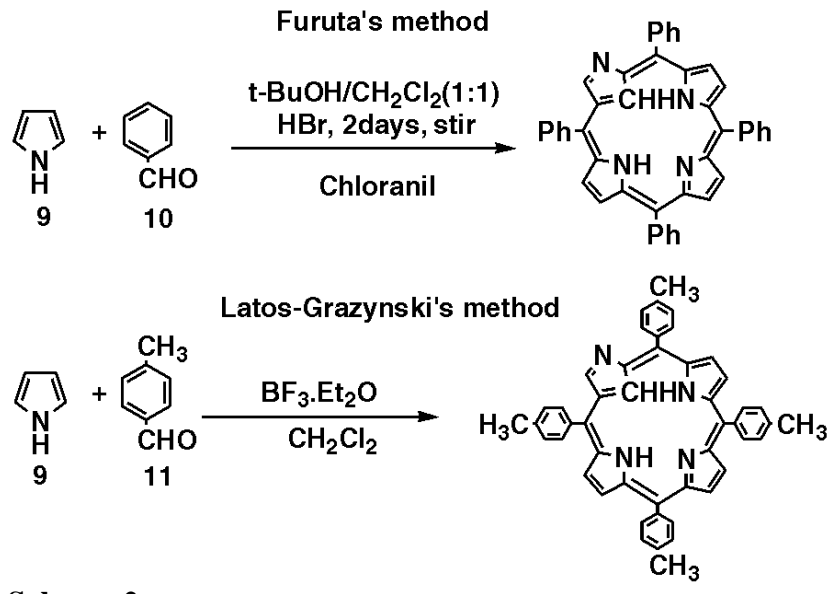

Scheme 2. 

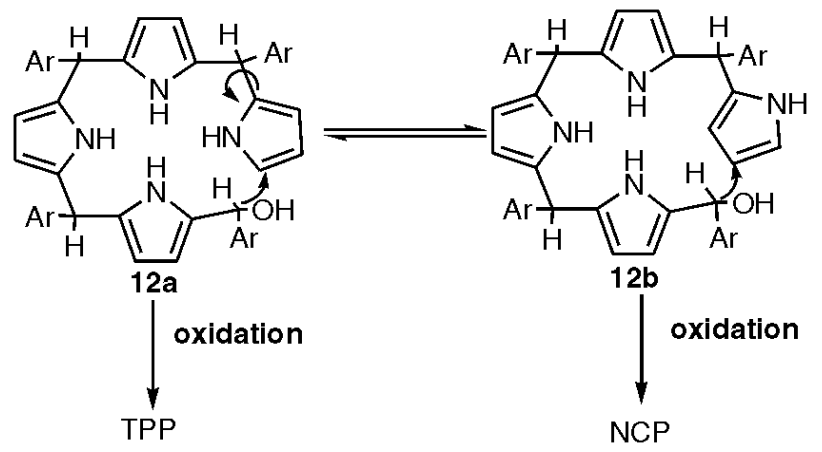

Scheme 3.

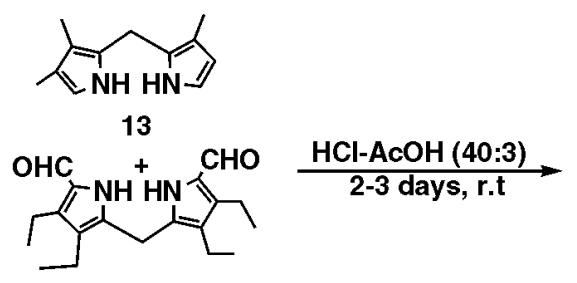

14

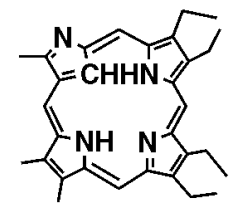

15

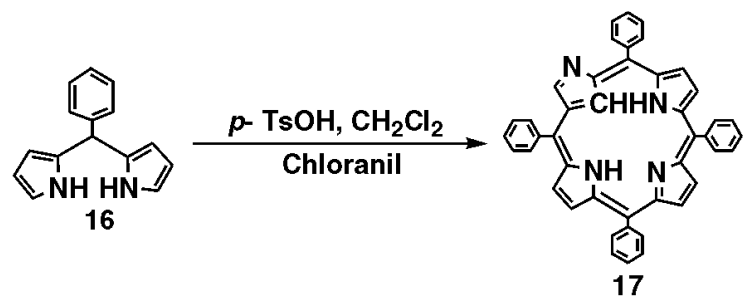

Scheme 4.

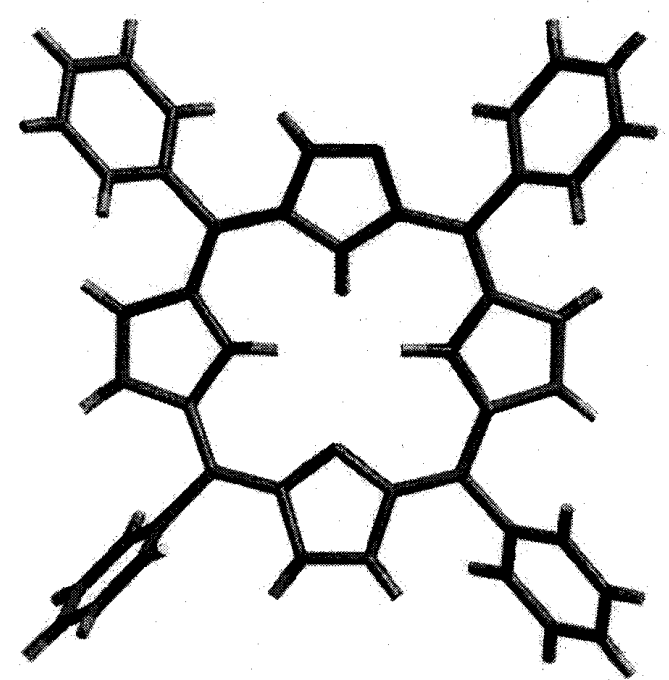

Figure 1. Crystal structure of $\mathrm{N}$-confused porphyrin (reproduced from ref. 37b). 
as one of the products in a one flask synthesis of a acid-catalysed reaction of pyrrole and aldehyde and this reaction is similar to that described earlier in scheme 2. Lash and coworkers reported the syntheses of hexa and heptaalkyl substituted inverted porphyrins by a $3+1$ condensation involving tripyrranedicarboxylic acid and pyrrole-2,4-dicarboxaldehyde ${ }^{44}$.

The remarkable ability to act as tetra coordinate ligands to form transition metal complexes involving a metal-carbon bond inside the porphyrin cavity has resulted in the formation of divalent simple and organometallic $\mathrm{Ni}(\mathrm{II})$ and $\mathrm{Ni}(\mathrm{III})$ complexes $^{37 \mathrm{a}, 45}$, rare organo $\mathrm{Cu}(\mathrm{II})$ complexes ${ }^{46}, \mathrm{Ag}(\mathrm{III})^{47}$ complexes with metal-carbon bonds. Recently, Furuta and coworkers have reported the formation of three types of Pd (II) complexes ${ }^{48}$, one involving inner co-ordination sites and the other two involving both inner and outer $\mathrm{N}$-coordination sites, resulting in the formation of double-decker complexes. In the reaction of $\mathrm{N}$-confused tetratolyl porphyrin and $\mathrm{Pd}(\mathrm{OAc})_{2}$, the formation of products was found to be solvent dependent ${ }^{48}$. Macrocycle 6 was also found to complex $\mathrm{Sb}(\mathrm{V})$ and the resulting metal complex was found to be a potential candidate for molecular wire component $^{49}$. The surprising ease of formation of metal-carbon bonds is attributed to the presence of an Arduengo-type aromatic carbene-like structure ${ }^{50}$, which makes the $\beta$-carbon inside the porphyrin cavity 'exotic' since it stabilizes a variety of oxidation states for transition metals, like Ni, used for complexation, which is otherwise difficult to obtain with the parent tetraphenyl porphyrin. Thus, owing to the inner core carbon and outward-pointing nitrogen, the coordination chemistry of $\mathbf{6}$ and $\mathbf{7}$ differs greatly from that of normal porphyrins. This characteristic multivalent nature of NCP is explained by the stabilization of the polarized metal-carbon bond by the deprotonation of the outward pointing $\mathrm{NH}$ in the confused pyrrole. $\mathrm{NCP}$ can act both as a divalent $\left(\mathrm{NCP}^{2-}\right)$ and trivalent $\left(\mathrm{NCP}^{3-}\right)$ ligand with $d^{8}$ metals like $\mathrm{Ni}^{2+}$ and $\mathrm{Ag}^{3+}$ as shown as type $\mathbf{I}$ and type II in figure 2, while in presence of $\mathrm{Pd}^{2+}$ salts it gives type III and type IV complexes, where metal coordination occurs both inside and outside the macrocycle ${ }^{51}$.

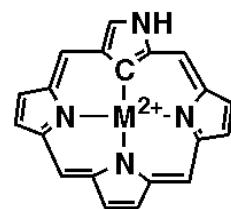

$\mathrm{NCP}^{2}$

typel

$(\mathrm{M}=\mathrm{Ni})$

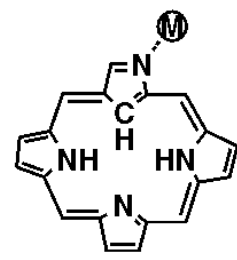

type III

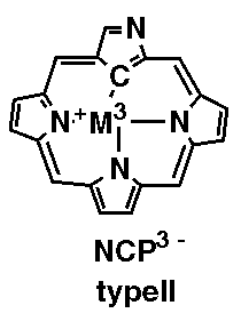

$(\mathrm{M}=\mathrm{Ni}, \mathrm{Ag}, \mathrm{Cu})$

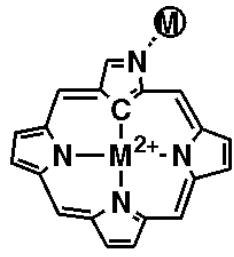

typelV

$$
\mathrm{M}=\mathbf{P d}^{2+}
$$

Figure 2. Metal binding modes of NCP. 
Core-modified inverted porphyrin, 2-aza-2-methyl-5,10,15,20-tetraphenyl-21-carbaporphyrin bearing a methyl group on the inverted pyrrolic nitrogen was formed from the methylation involving methyl iodide ${ }^{52}$. Apart from trying to obtain various mutant porphyrins, attempts were made to core-modify NCP by substituting one of the core NHs with $\mathrm{O}, \mathrm{S}$ groups. Scheme 5 describes the synthetic methodology adopted for the formation of the products. Thus the isomers of 21-oxaporphyrin and 21-thiaporphyrin, 21a and 21b, with an inverted pyrrole ring in the position trans to the furan or thiophene rings were synthesized by the reaction between 2,5-bis(phenyl $\alpha$-hydroxymethyl) pyrrole $\mathbf{1 8}$ and modified tripyrrin 20 and in $5 \cdot 5-8 \%$ yield respectively ${ }^{53}$.

Very recently Latos-Grazynski and coworkers reported a pyrrole-inverted isomer of 5,10,15,20-teraaryl-21-selena porphyrin i.e. 5,10,15,20-tetraaryl-22-selenaporphyrin $\mathbf{2 4}$ in $1 \%$ yield where the selenophene ring is cis with respect to the inverted pyrrole ring (scheme 6) from the precursor diol 22 and tripyrrin ${ }^{54} \mathbf{2 3}$.

Latos-Grazynski and coworkers also reported the formation of a new isomer of 5, 10,15,20-tetraphenyl-21-thiaporphyrin with an inverted thiophene ring, i.e. 2-thia5,10,15,20-tetraphenyl-21-carbaporphyrin 27 resulting from the condensation reaction of 2,4-bis(phenyl hydroxymethyl) thiophene 25 with pyrrole and benzaldehyde via a onepot two-step reaction in $4 \%$ yield or by the $3+1$ condensation of the thiophene precursor and 5,10-diphenyl tripyrrin $\mathbf{2 6}$ in $2 \%$ yield as shown in scheme $7^{55}$.

\section{Doubly N-confused porphyrins}

Doubly $\mathrm{N}$-confused porphyrin $\left(\mathrm{N}_{2} \mathrm{CP}\right) 7$ was synthesized in $2 \%$ yield by Furuta and coworkers $^{39}$ via the acid catalysed condensation of perfluorobenzaldehyde 29 with $\mathrm{N}$ confused dipyrromethane 28 in $\mathrm{CHCl}_{3}$ containing a trace of $\mathrm{EtOH}$ followed by oxidation<smiles>[Y]S(=O)(=O)O[Na]</smiles>

$R=H$

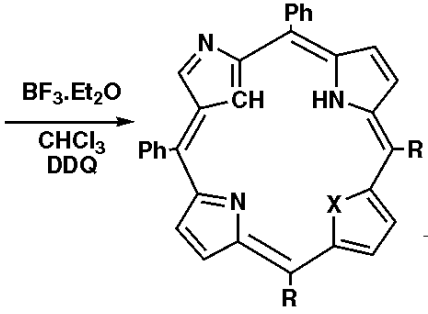

21a $X=S$

21b $X=0$

Scheme 5.

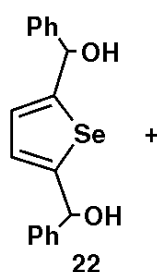

22

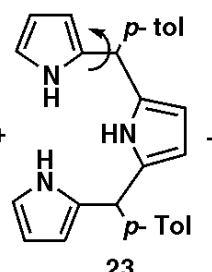

23

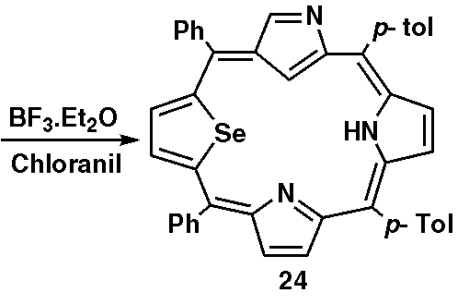

24

Scheme 6. 


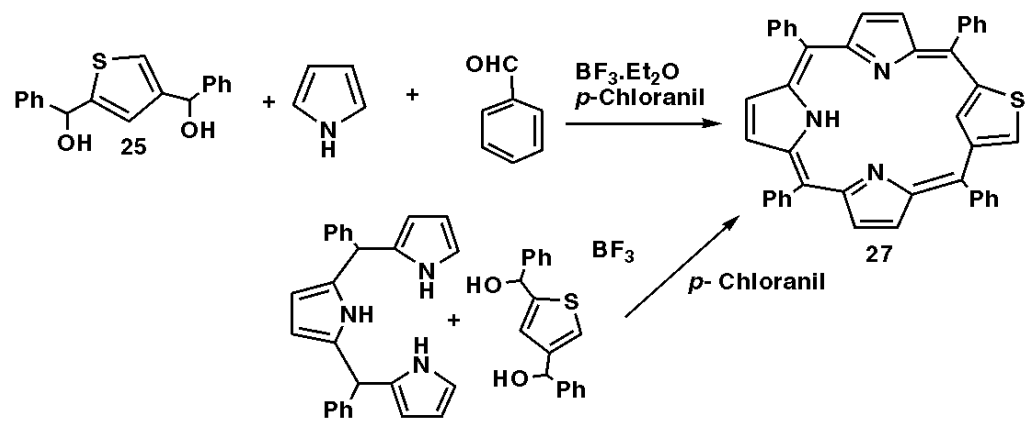

Scheme 7.

26

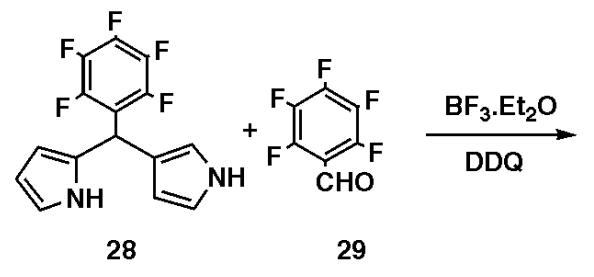

Scheme 8.

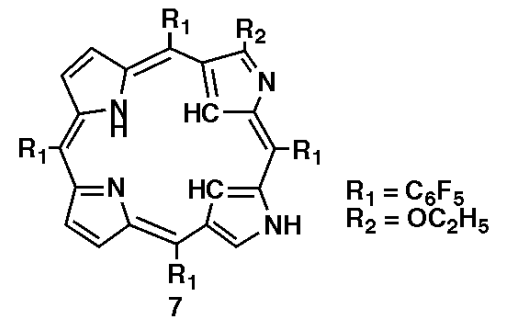

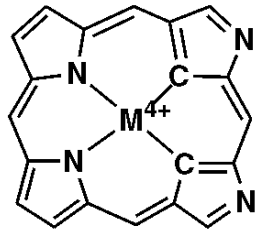

$\mathrm{N}_{2} \mathrm{CP}^{4-}$

$$
\begin{array}{lr}
\mathrm{N}_{2} \mathrm{CP}^{2-} & \mathrm{N}_{2} \mathrm{CP}^{3-} \\
\mathrm{M}=\mathrm{Pd} & \mathrm{M}=\mathrm{Ag}, \mathrm{Cu}
\end{array}
$$

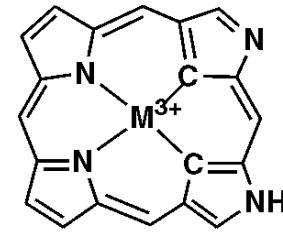

Figure 3. Metal binding modes for $\mathrm{N}_{2} \mathrm{CP}$.

with 2,3-dichloro-5,6-dicyano-1,4-benzoquinone (DDQ) as described in scheme 8. Small amounts of $\mathrm{EtOH}$ and bromide were found to be effective for this reaction. An attempt using EtOH-free dry $\mathrm{CHCl}_{3}$ to avoid generating products containing ethoxy substituents led to trace amounts of $\mathrm{N}_{2} \mathrm{CP}$.

This macrocycle was found to stabilize complexes containing rare $\mathrm{Ag}(\mathrm{III})$ and $\mathrm{Cu}(\mathrm{III})$ centres $^{39}$. Furuta et al have shown that similar reaction with 2-ethoxy-5,10,15,20-tetrakis (pentafluorophenyl) derivative of 7 in toluene, unexpectedly yielded inner C-tolylated $\mathrm{Pd}(\mathrm{II})$ complex instead of the expected $\mathrm{Pd}(\mathrm{IV})$ or $\mathrm{Pd}(\mathrm{III})$ complex ${ }^{56}$. The multivalent property is common for all members of the NCP family and hence $\mathrm{N}_{2} \mathrm{CP}$ exhibits divalent nature $\left(\mathrm{N}_{2} \mathrm{CP}^{2-}\right)$ in the case of $\mathrm{Pd}(\mathrm{II})$, trivalent nature $\left(\mathrm{N}_{2} \mathrm{CP}^{3-}\right)$ in the case of $\mathrm{Ag}(\mathrm{III})$ and $\mathrm{Cu}(\mathrm{III})$, while tetravalent nature can also be expected as shown in figure $3^{39}$. The crystal structure of $\mathrm{N}_{2} \mathrm{CP}$ is shown in figure 4 . 


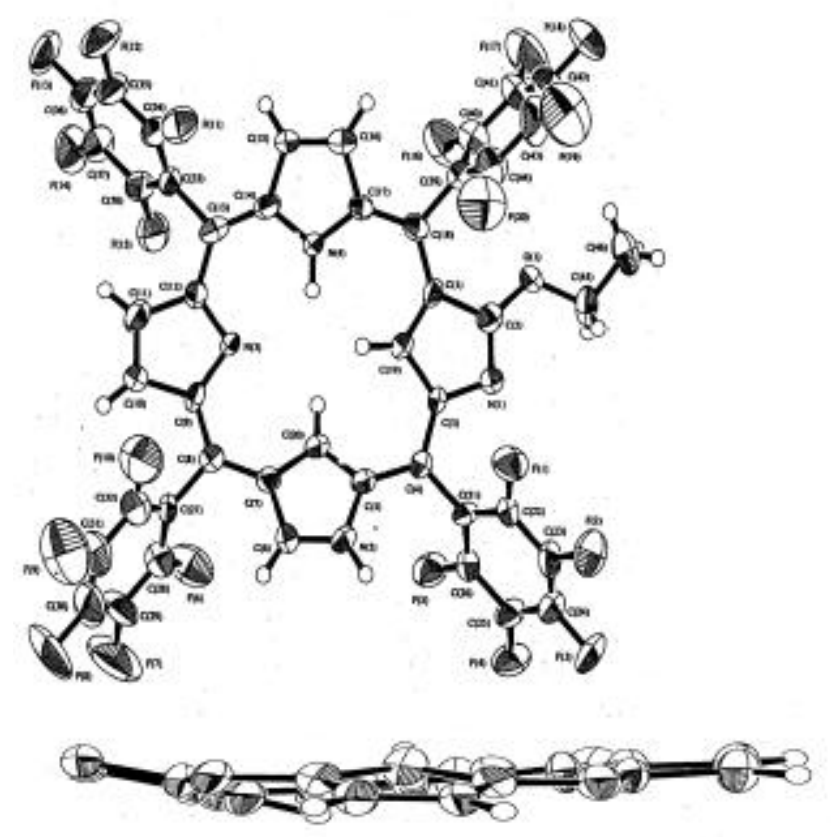

Figure 4. Crystal structure of 7 plane view (top) and side view (bottom) (pentaflourophenyl, ethoxy groups were omitted for clarity) (reproduced from ref. [39]).

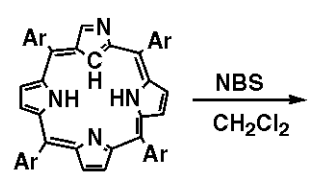

6

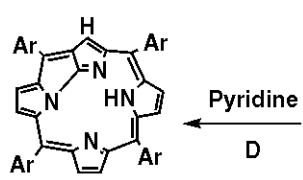

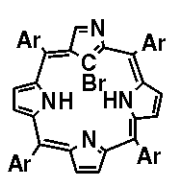

30

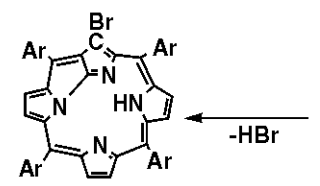

32

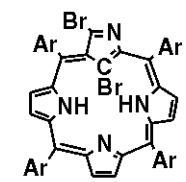

31a Pyridine

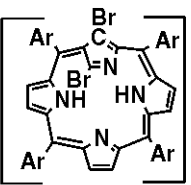

$31 b$

Scheme 9.

\section{N-fused porphyrin}

$\mathrm{N}$-fused porphyrin ${ }^{40}$ (NFP) 8 was accidentally obtained from a pyridine solution of brominated N-confused porphyrin. When a solution of NCP was treated with $\mathrm{N}$ bromosuccinimide (NBS) for $5 \mathrm{~min}$ at room temperature monobrominated-NCP 30 in $90 \%$ yield was formed which on further bromination by addition of 2 eq. NBS afforded 
dibrominated NCP 31 in $70 \%$ yield. The monobrominated derivative of NFP 32 was formed at room temperature after $8 \mathrm{~h}$ in pyridine and the substituented bromine was replaced by hydrogen resulting in the formation of NFP $\mathbf{8}$ simply by refluxing in pyridine as shown in scheme 9 . Figure 5 shows the crystal structure of NFP.

\section{Pentapyrrolic systems}

Expanded porphyrins ${ }^{7}$ containing five pyrrolic units are connected by different numbers of methine bridges, which can be either maintained as four or increased or decreased. These conjugated pentapyrrolic macrocycles reported till date can be classified into two groups, namely aromatic pentaphyrins (33-38) and nonaromatic pentapyrrolic system 39 shown in chart 1 .

\subsection{Aromatic systems}

6.1a Sapphyrins-[22] pentaphyrins-(1.1.1.1.0): Sapphyrins 33 are [22] pentaphyrins (1.1.1.1.0), which are aromatic and are the first expanded porphyrins to be reported ${ }^{57}$. RB Woodward coined the trivial name 'sapphyrin' for this macrocycle due to its intense blue-green colour in organic solvent. Woodward and coworkers ${ }^{57}$ isolated this

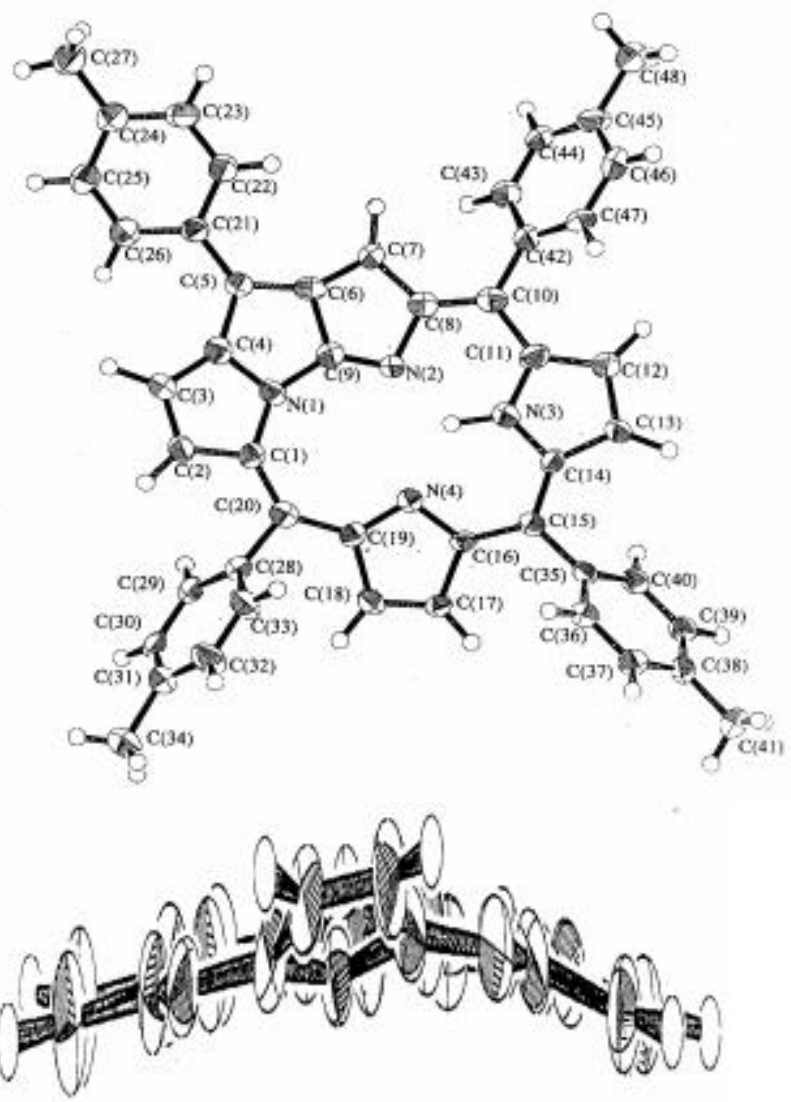

Figure 5. Crystal structure of $\mathbf{8}$ taken from ref. [40]. 
serendipitously during the course of synthesis of the corrin core of vitamin $\mathrm{B}_{12}$ in 1966 . Sapphyrin was obtained in the $4+1$ condensation reaction between the linear tetrapyrrolic precursor, bipyrrolyldipyromethane ${ }^{8} \mathbf{4 0}$ and 2,5-diformyl-3,4-dimethyl pyrrole $\mathbf{4 1}$ in acid medium as shown in scheme 10. This synthesis involved multi steps and the key precursors were hard to make.

Later, Woodward's group ${ }^{8}$ and Johnson and coworkers ${ }^{58}$ independently tried a $3+2$ condensation involving bipyrrole dialdehyde $\mathbf{4 2}$ with a tripyrrane $\mathbf{4 3}$ catalysed by acid followed by air oxidation, which went on to become the most widely used methodology for the synthesis of sapphyrin $\mathbf{4 4}$ (scheme 11). Woodward and coworkers, using a pyrrolyl bipyrrole and diformyl dipyrromethane to produce the desired sapphyrin in $35 \%$ yield, implemented an alternative $3+2$ methodology but the difficulty in precursor synthesis limited the utility of the above methods.

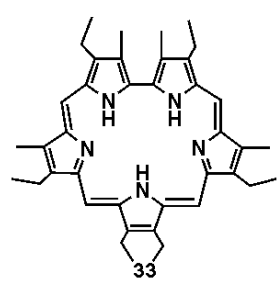

[22]pentaphyrin(1.1.1.0)

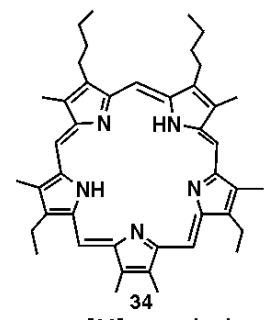

[22]pentaphyrin-

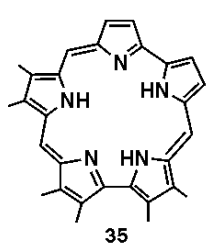

35

[22]pentaphyrin-

(1.1.0.1.0)

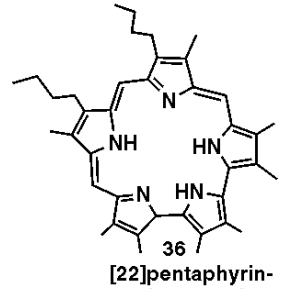

22]pentaphyrin-
$(1.1 .1 .0 .0)$

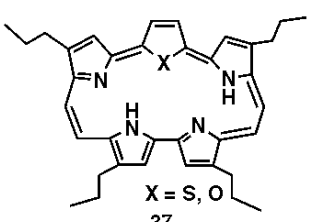

[22]pentaphyrin-

$(2.0 .2 .0 .0)$

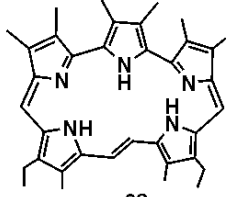

[22]pentaphyrin-

(2.1.0.0.1)

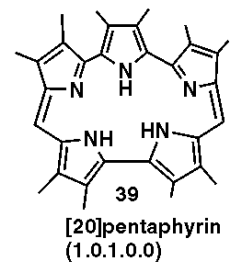

Chart 1.

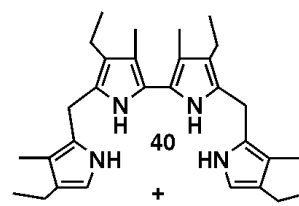

$\mathrm{OHC}_{Y}^{\mathrm{H}}{ }^{\mathrm{CHO}}$

41
$\mathrm{HCO}_{2} \mathrm{H}, \mathrm{MeOH}$

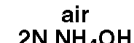

IN HCI

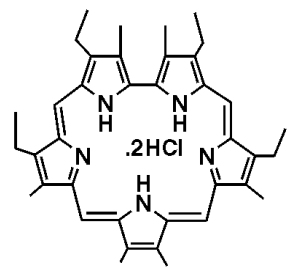

33

Scheme 10. 
Woodward and coworkers have exploited one-pot synthesis of sapphyrins first by the reaction of 3,4-dimethyl pyrrole 45 with pyrrole dialdehyde 41 to produce sapphyrin $\mathbf{4 6}$ in $<1 \%$ yield $^{8}$. Later Sessler and coworkers synthesized $\mathbf{4 8}$ from acid catalysed reaction of pyrrole, bipyrroledialdehyde $\mathbf{4 7}$ and benzaldehyde in $10 \%$ yield $^{58}$. Latos-Grazyski and coworkers reported the first meso-tetraphenyl sapphyrin 49 from the reaction of benzaldehyde and pyrrole in 1:3 molar ratios under oxidative acid catalysis in $1.1 \%$ yield $^{59}$. Scheme 12 describes the above reactions. Dolphin's group reported the efficient synthesis of $\mathbf{4 8}$ and 49 by appropriately choosing 5,10-diphenyltripyrrane and bipyrrole precursors ${ }^{60}$. Smith and coworkers reported the formation of sapphyrin in $20 \%$ yield from biladiene and formyl pyrrole ${ }^{61}$.

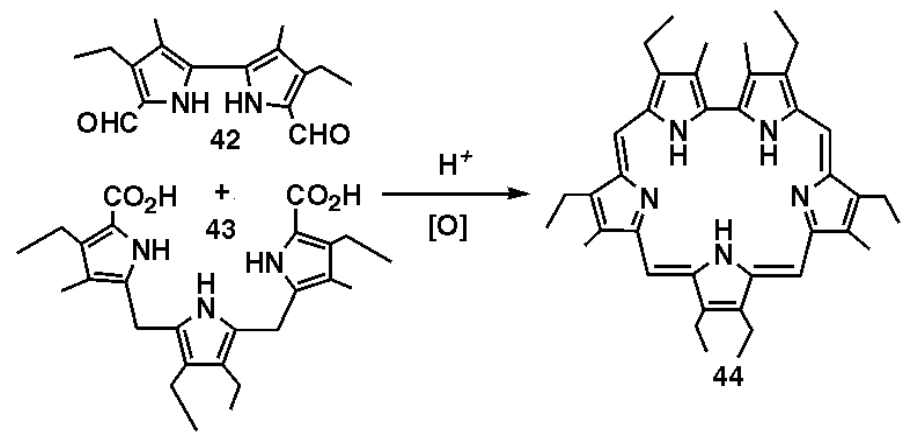

Scheme 11.

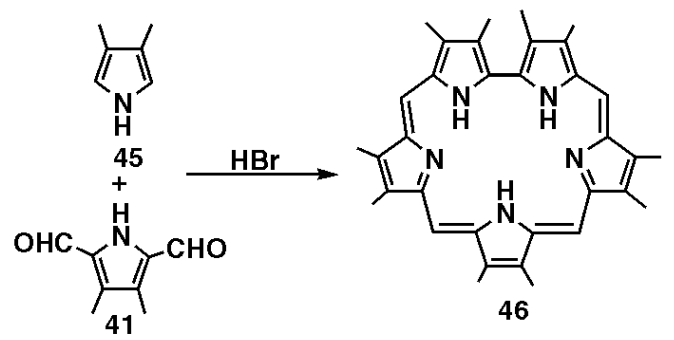

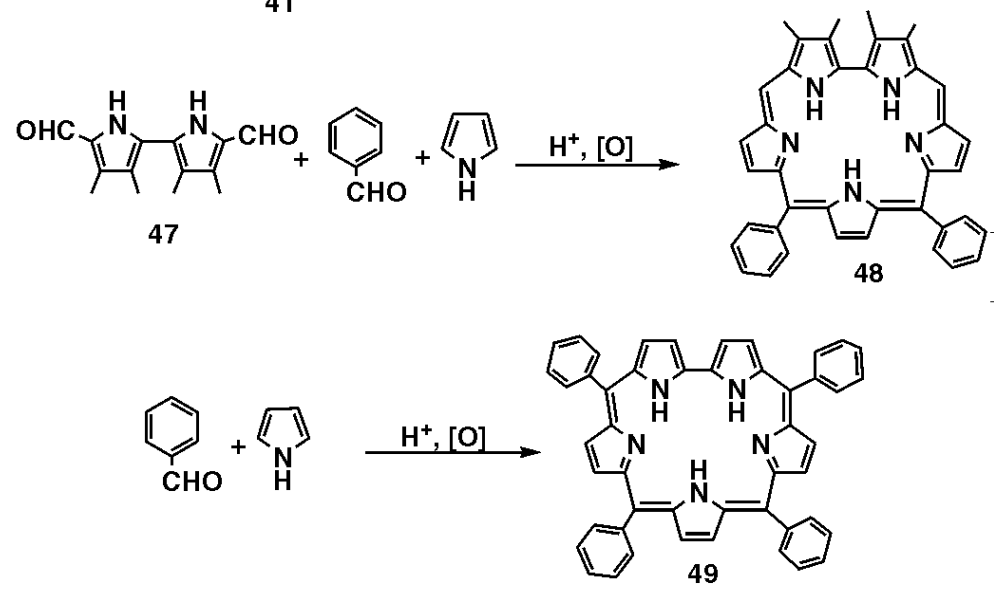

Scheme 12. 
Recently Lindsey's group has improved the yield of sapphyrins and N-confused porphyrins in Rothemund type of reaction by using appropriate reaction conditions ${ }^{43 a}$. Chandrashekar and coworkers ${ }^{42}$ have shown that with a single precursor dipyrromethane bearing phenyl group, sapphyrin $\mathbf{5 0}$ is obtained with TPP and meso-tetraphenyl rubyrin when the acid used for catalysis is trifluoroacetic acid (TFA) as shown in scheme 13.

Substitution of one or more pyrrolic units with other heterocycles such as furan, thiophene and selenophene leads to heteroasapphyrins. Core modification leads to changes in cavity size, electronic structure. There are only limited reports on the syntheses and characterization of core modified expanded porphyrins in the literature. Johnson and coworkers developed the first example of such a system when they tried to generate heteroatom analogues of corroles starting from diformylbifuran $\mathbf{5 1}$ and dipyrromethane $\mathbf{5 2}$ synthesizing dioxa sapphyrin $\mathbf{5 3}$ along with the sought after dioxacorrole as shown in scheme $14^{62}$.

Sessler and coworkers ${ }^{63}$ have synthesized a series of $\beta$-substituted sapphyrins containing one or more heteroatoms by the usual $3+2$ methodology selecting appropriate precursors as explained in scheme 11. Chandrashekar and coworkers ${ }^{64}$ have reported a series of meso-aryl sapphyrins $\mathbf{5 6}$ where $\mathrm{O}, \mathrm{S}$ and Se replace two or three core nitrogens by an easy and efficient MacDonald 3+2 condensation involving tripyrromethanes $\mathbf{5 4}$ and diols 55 in high yield (16-63\%) and the product distribution varies with the nature and concentration of acid used (scheme 15). Another method reported by the same group to synthesize core-modified sapphyrins involves an unprecedented coupling of tripyrromethane $\mathbf{5 4}$ resulting in the formation of diheteroatom substituted meso-aryl sapphyrins 57 in moderate yields along with disubstituted meso-aryl porphyrins and meso-aryl rubyrins as shown in scheme $15^{65}$. During the course of this work, LatosGrazynski and coworkers reported the formation of $\mathbf{5 7}$ in low yield in a Rothemund reaction of 2,5-disubstituted thiophene diol and pyrrole ${ }^{63 \mathrm{~d}}$. The first carba sapphyrin $\mathbf{6 0}$ was reported by Lash and coworkers through a $(4+1)$ MacDonald condensation between a tetrapyrrole dicarboxylic acid $\mathbf{5 8}$ and diformyl indene $\mathbf{5 9}$ as shown in scheme $16^{66}$.

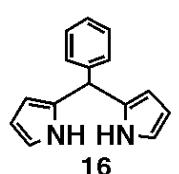

1 equiv. TFA, $\mathrm{CH}_{2} \mathrm{Cl}_{2}$

Chloranil

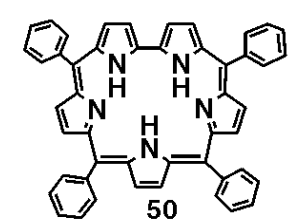

Scheme 13.
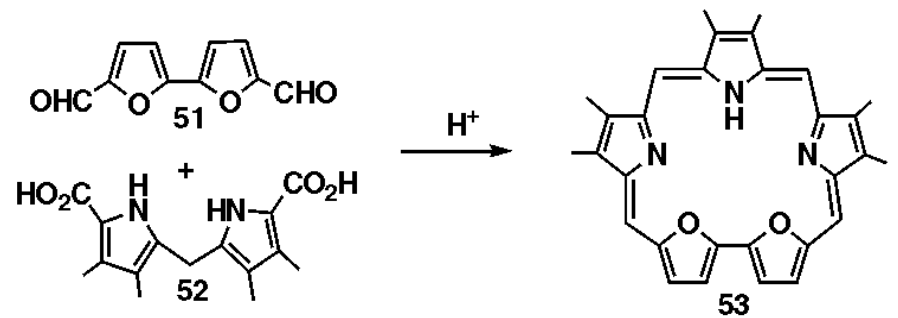

Scheme 14. 
6.1b Pentaphyrins-[22] pentaphyrin-(1.1.1.1.1): In 1983 Gossauer and coworkers obtained pentaphyrin $\mathbf{3 4}^{11,12,67}$ which has a Franck nomenclature [22] pentaphyrin (1.1.1.1.1) by an $\mathrm{HBr}$ catalysed oxidative condensation between diformyltripyrrane $\mathbf{6 1}$ and dipyrromethane $\mathbf{6 2}$ in $31 \%$ yield as shown in scheme 17. More recently mesodiphenyl pentaphyrin was reported by TFA catalysed $3+2$ condensation by Dolphin and coworkers ${ }^{60}$. Pentathiapentaphyrin ${ }^{68,69}$ and pentaselenapentaphyrin ${ }^{70}$ were reported by Vogel's group. Very recently, Furuta and coworkers reported the formation of N-fused normal type $22 \pi$ electronic pentaphyrin containing a fused tripentacyclic ring from the Rothemund reaction of aldehyde and pyrrole in presence of $\mathrm{BF}_{3} \cdot \mathrm{Et}_{2} \mathrm{O}$ and $\mathrm{DDQ}^{71}$.

6.1c Smaragdyrins-[22] pentaphyrin-(1.1.0.1.0): Another pentaphyrin 35 with a trivial name 'smaragdyrin or norsapphyrins' are [22] pentaphyrin (1.1.0.1.0) ${ }^{8,72}$ that has only three meso carbons that bear a structural relationship with sapphyrins as corrole does to porphyrin. It was first reported as a dioxa smaragdyrin 64 from the $3+2$ reaction of a

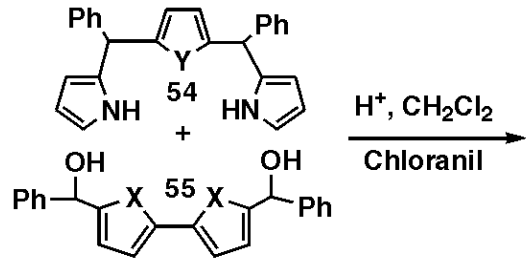

$\mathrm{X}=\mathrm{S}, \mathrm{Se}, \mathrm{O}$

$\mathrm{Y}=\mathrm{S}, \mathrm{Se}, \mathrm{O}, \mathrm{NH}, \mathrm{N}\left(\mathrm{CH}_{3}\right)$

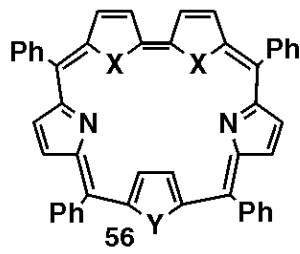

$X=S$, Se, $O$

$\mathrm{Y}=\mathrm{S}, \mathrm{Se}, \mathrm{O}, \mathrm{NH}, \mathrm{N}\left(\mathrm{CH}_{3}\right)$
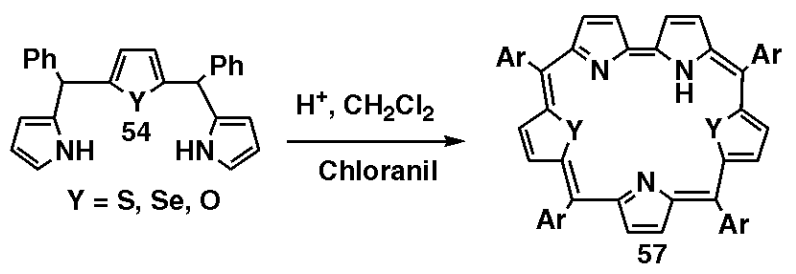

$\mathrm{Y}=\mathrm{S}, \mathrm{Se}, \mathrm{O}$

Scheme 15.
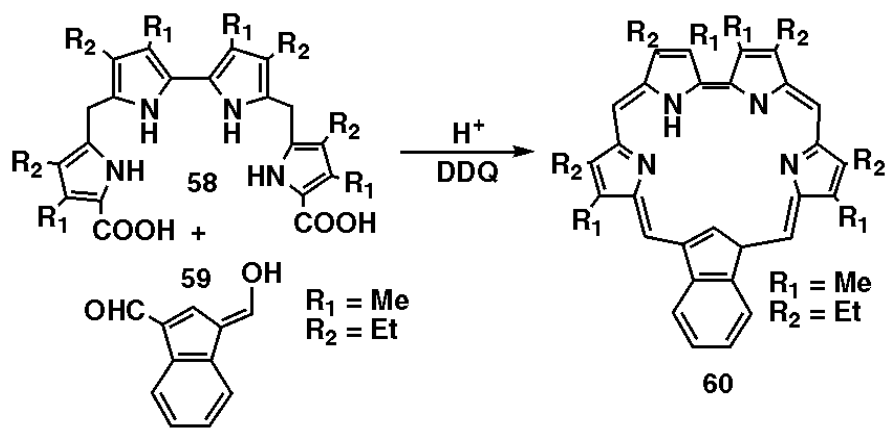

Scheme 16. 
pyrrolyl bipyrrole $\mathbf{6 3}$ and diformyl bifuran $\mathbf{5 1}$ as shown in scheme 18. An all-aza analogue $\mathbf{3 5}$ was also synthesized but was found to be sensitive towards light and was decomposed in the silica gel column. Recently Chandrashekar and coworkers have published a facile and efficient synthesis for the formation of meso-aryl smaragdyrin bearing one $\mathrm{S}$ or $\mathrm{O}, \mathbf{6 5}$ by an oxidative coupling reaction involving tripyrrane $\mathbf{5 4}$ and dipyrromethane $\mathbf{1 6}$ (scheme 19) ${ }^{73}$.

6.1d Isosmaragdyrins-[22] pentaphyrin-(1.1.1.0.0): Sessler and coworkers synthesized a new contracted sapphyrin namely 'isosmaragdyrin' or [22] pentaphyrin (1.1.1.0.0) 36 via a terpyrrole dialdehyde 66 and dipyrromethane diacid $67^{10}$. The same group also reported the synthesis of mono oxa isosmaragdyrin $\mathbf{6 8}$ using a similar $3+2$ methodology as shown in scheme 20 .

6.1e Ozaphyrins-[22] pentaphyrin-(2.0.2.0.0): Johnson and Ibers prepared another $22 \pi$ aromatic macrocycle, which is an isomer of mono oxasapphyrin that was, assigned a trivial name 'ozaphyrin' due to its Oz-like emerald green colour in solution. It is a [22] pentaphyrin-(2.0.2.0.0), 37 which was prepared by coupling the bis (pyrrolyl) furan/thiophene 69 with diformyl bipyrrole 70 under McMurry conditions as shown in
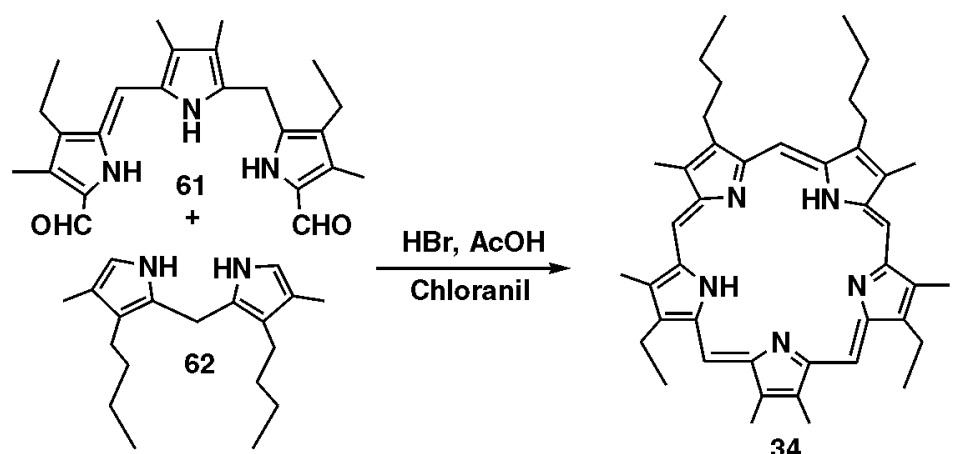

Scheme 17.
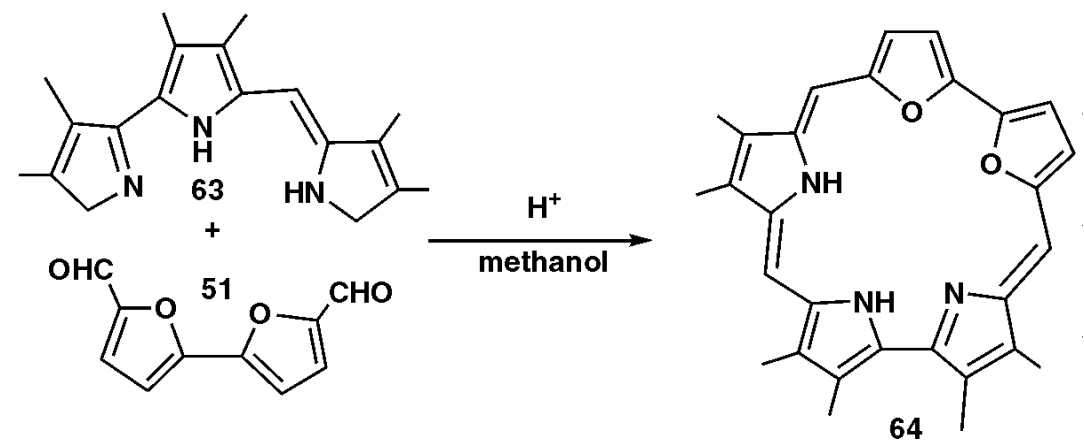

Scheme 18. 

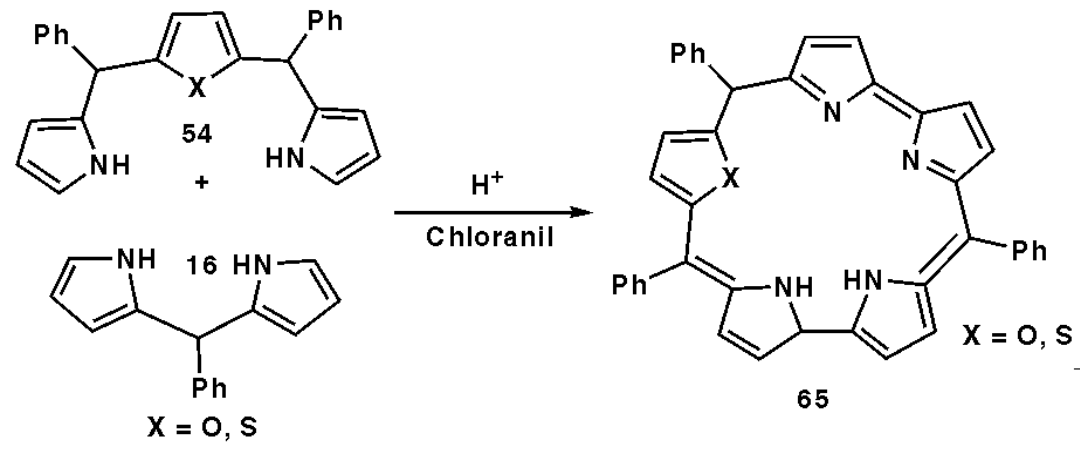

Scheme 19.

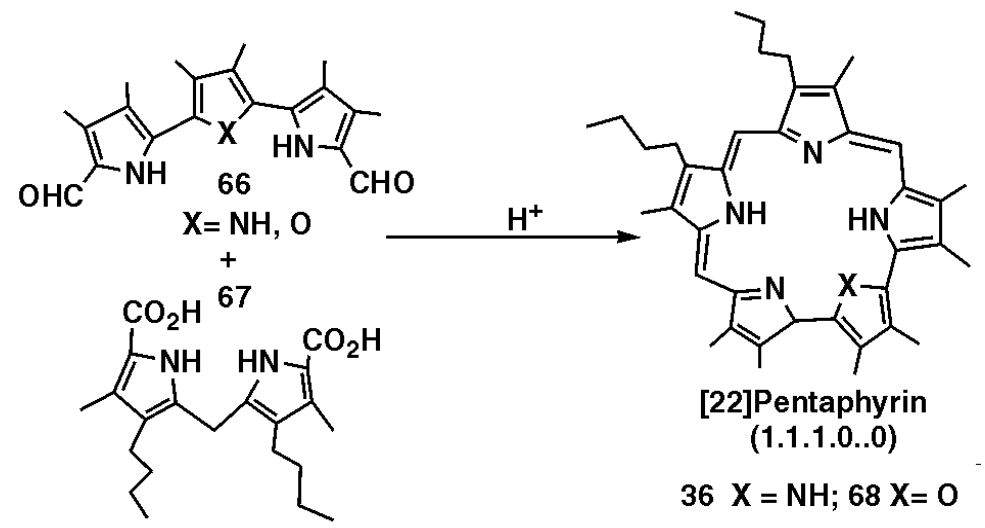

Scheme 20.

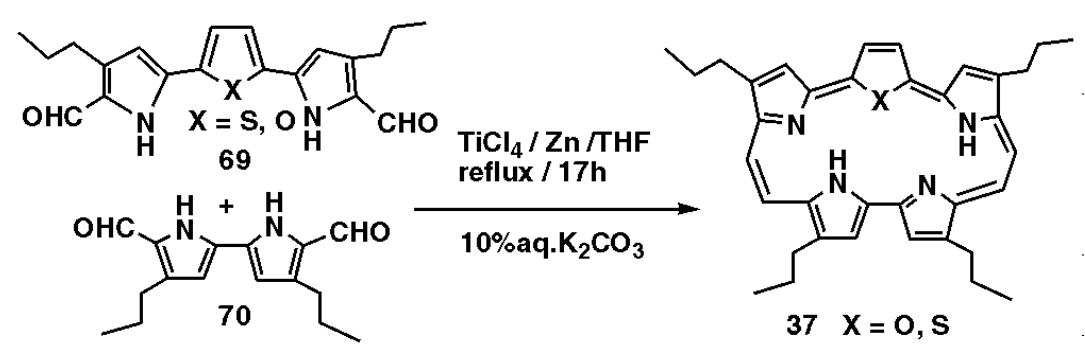

Scheme 21.

scheme $21^{19,21}$. In addition to the expected ozaphyrin, the respective porphycene 2 and bronzaphyrin, which is a six membered expanded porphyrin, were formed.

6.1f Dehydropentaphyrin-(2.1.0.0.1) and [22] pentaphyrin-(2.1.0.0.1): [22] Pentaphyrin (2.1.0.0.1) 38 was synthesized by condensing terpyrrole 71 with an alkyne bridged bipyrrole 72 under standard MacDonald conditions giving rise to $22 \pi$ aromatic macrocycle dehydropentaphyrin 73. This on treatment with poisoned Lindlar catalyst gave rise to the expected compound $\mathbf{3 8}$ as shown in scheme $22^{74}$. 
6.2 Conjugated nonaromatic systems

6.2a Orangarin-[20] pentaphyrin-(1.0.1.0.0): The smallest pentapyrrolic system synthesized to date is 'orangarin' 39, which is a [20] pentaphyrin-(1.0.1.0.0). This compound was prepared by acid-catalysed condensation between terpyrrole $\mathbf{7 1}$ and bipyrrole dialdehyde 47 as shown in scheme $23^{13}$.

6.2b Other systems: Other aromatic systems having pentapyrrolic systems include pentaoxa and pentathia [30] pentaphyrin-(2.2.2.2.2) where each furan/thiophene heterocycle has been bridged by two meso carbons ${ }^{75-77}$. Another macrocycle pentaphyrin-(5.5.5.5.5) was also reported which can be treated as decavinylogously enlarged pentaphyrin ${ }^{78}$.

\section{Hexapyrrolic systems}

Hexapyrrolic macrocycles are expanded porphyrins with six pyrrolic/heterocyclic units connected by bridging carbon atoms. The number of meso carbons can be four or can be increased and decreased. Some of the nonaromatic and aromatic hexaphyrins are shown in chart 2.

\subsection{Aromatic systems}

7.1a Rubyrins-[26] hexaphyrin-(1.1.0.1.1.0): This expanded porphyrin $\mathbf{7 4}$ which is a [26] hexaphyrin-(1.1.0.1.1.0) was reported by Sessler et al in 1991 by condensing tetrapyrrolic precursor $\mathbf{8 1}$ with diformyl bipyrrole $\mathbf{8 2}$ under acid catalysis and subsequent air oxidation as shown in scheme $24^{18}$. The resulting macrocycle was assigned the trivial name 'rubyrin' due to its dark orange-red colour in dichloromethane. The hexathiarubyrin
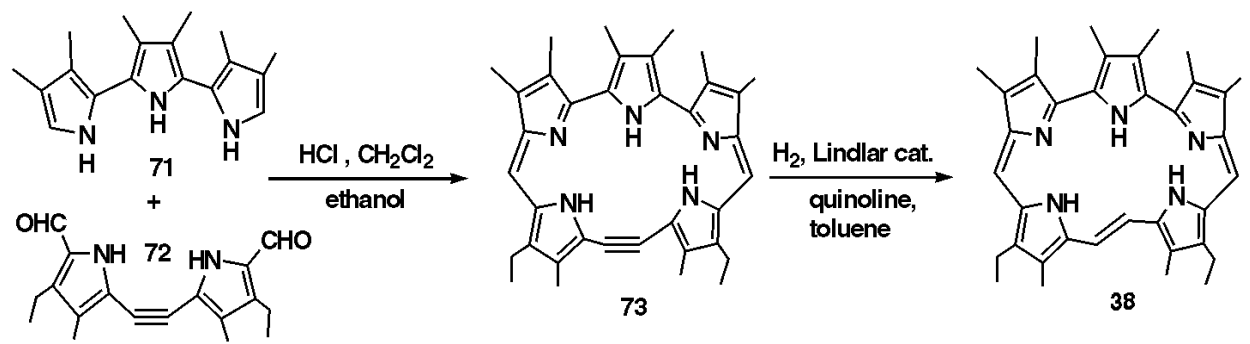

Scheme 22.

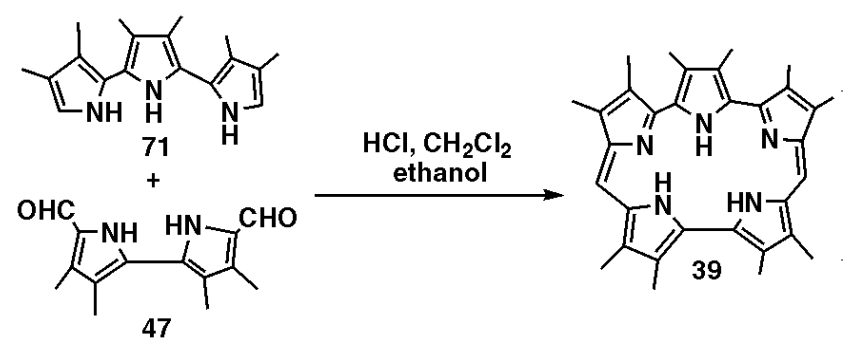

Scheme 23 . 


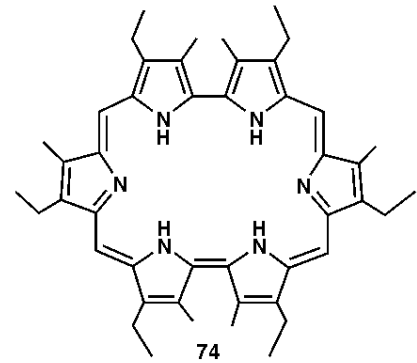

[26]hexaphyrin (1.1.0.1.1.0)

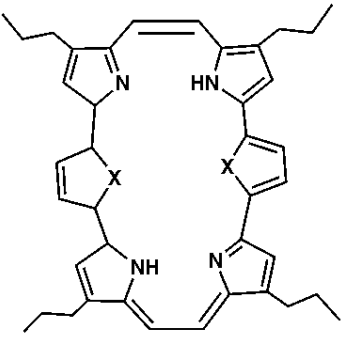

76

$\mathrm{X}=\mathrm{S}, \mathrm{O}$ [26]hexaphyri
$(2.0 .0 .2 .0 .0)$

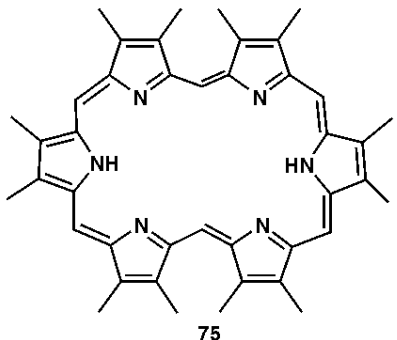

[26]hexaphyrin (1.1.1.1.1.1)
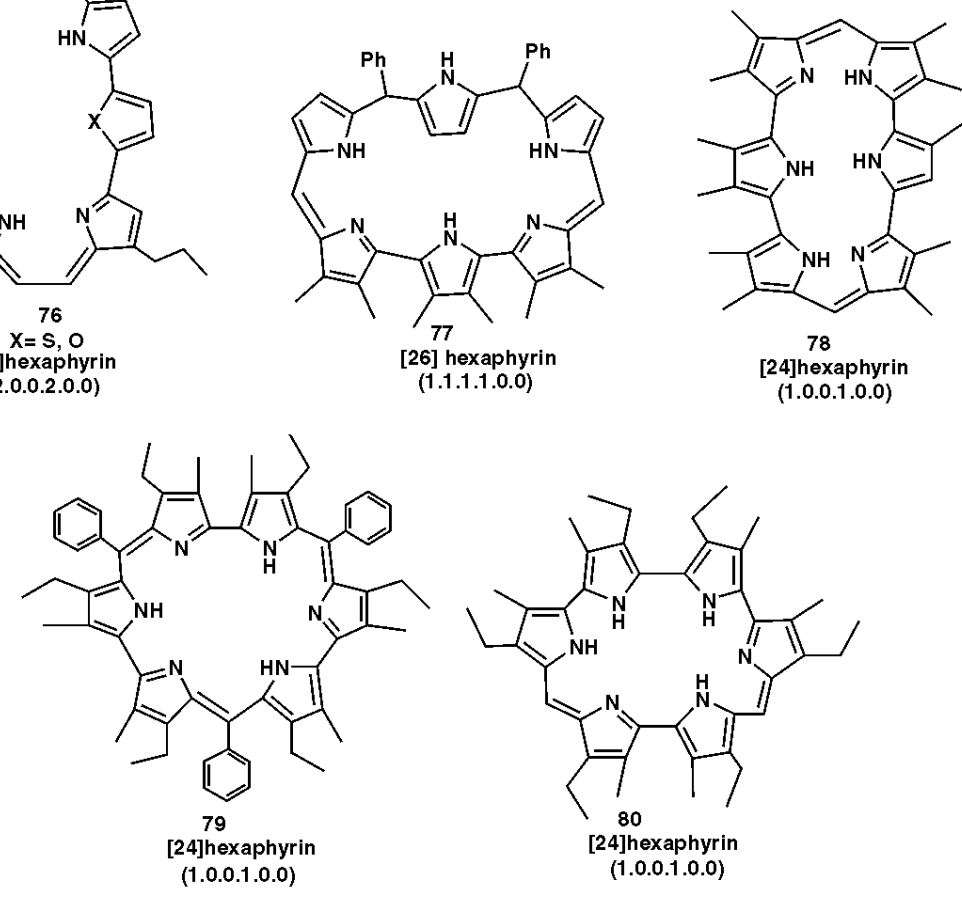

Chart 2.
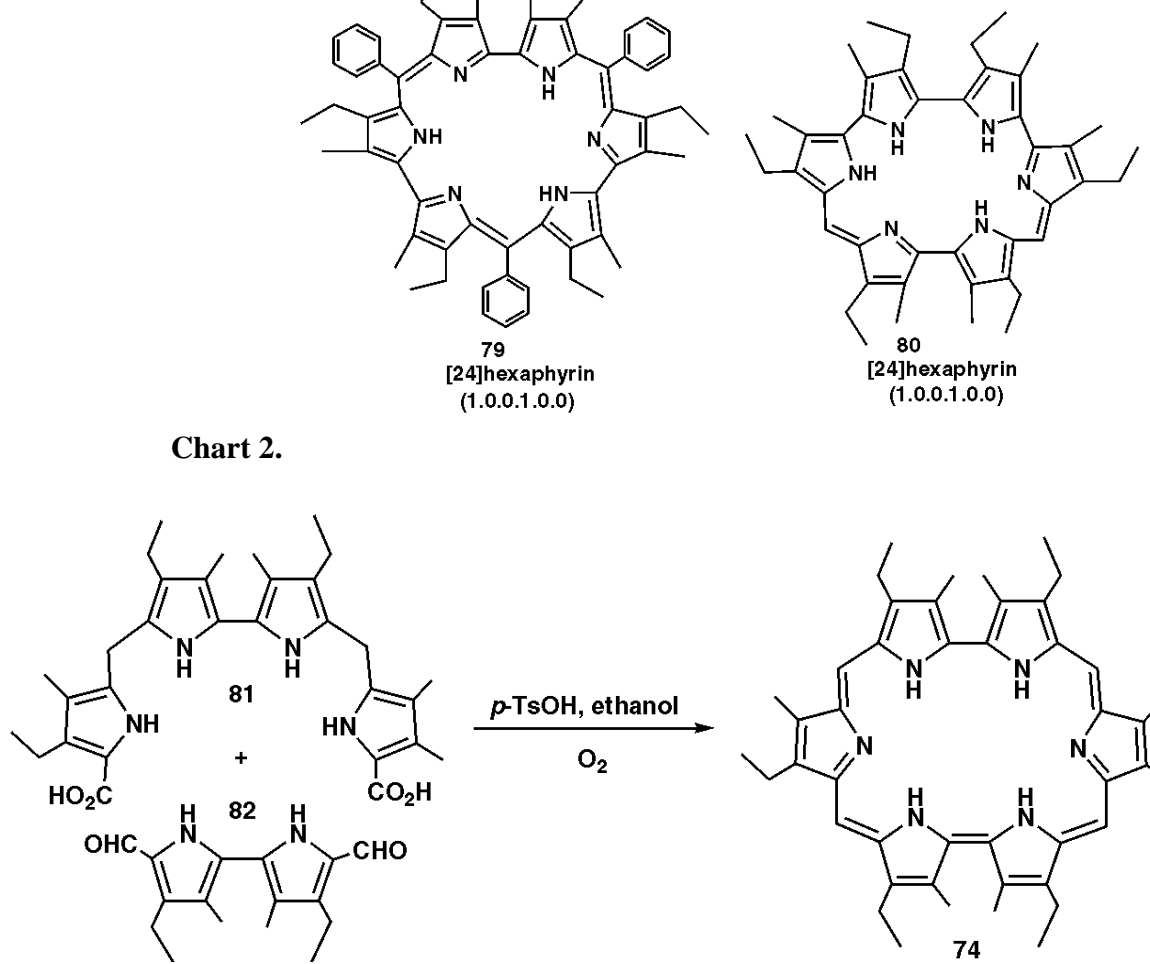
was synthesized by Vogel and coworkers in about $20 \%$ yield by the acid catalyzsed condensation between dithiophene dialcohol and 3,4-diethyl thiophene ${ }^{7 b}$.

Chandrashekar and coworkers reported an easy efficient methodology for first tetrathia/tetraselena/tetraoxa meso-tetraphenylrubyrins 83, by the $2+1$ condensation of 5,5'bis(phenyl hydroxy methyl) 2,2'-bithiophene/biselenophene/bifuran diol $\mathbf{5 5}$ and pyrrole under Lindsey conditions followed by oxidation with chloranil as shown in scheme 25 in $19-28 \%$ yield $^{79,80}$. The same group reported the formation of rubyrins containing three heteroatoms by acid catalyzed $4+2$ condensation of tetrapyrrane $\mathbf{8 4}$ and corresponding diol 55 under TFA catalysis yielding 20-28\% yield of expected rubyrins 85 and $\mathbf{8 6}$ as shown in scheme $26^{80}$.

Another report from the same group describes an unprecedented coupling of tripyrranes $\mathbf{5 4}$ in presence of protic acid yielding rubyrins $\mathbf{8 6}$ as one of the products along with sapphyrins and porphyrins. The mixed coupling of tripyrranes $\mathbf{5 4}$ yielded rubyrins 87 bearing three heteroatoms. The reaction scheme is shown in scheme $27^{65,81}$.

7.1b Hexaphyrin-[26] hexaphyrin-(1.1.1.1.1.1): Hexaphyrin 75 was first reported by Gossauer and coworkers ${ }^{12,67}$. It was synthesized by the acid-catalysed $3+3$ condensation of $\alpha$-free tripyrranes $\mathbf{8 8}$ and tripyrrane dialdehyde $\mathbf{8 9}$ as shown in the scheme 28 .

First meso-aryl hexaphyrin was reported by Dolphin and coworkers through Lindsey type condensation between 5,10-diphenyl tripyrrane and benzaldehyde, and was found unstable ${ }^{60}$. Cavaleiro and coworkers, through the Rothemund type synthesis involving pentafluorobenzaldehyde and pyrrole reported the first stable meso-aryl hexaphyrin ${ }^{82}$.

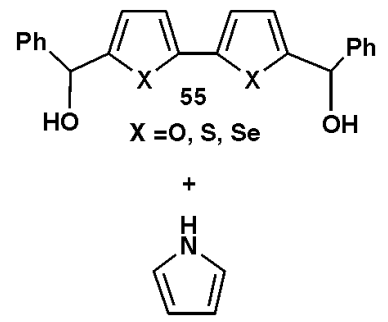

Scheme 25.
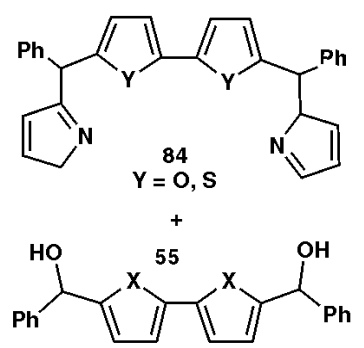

$\mathrm{X}=\mathrm{S}, \mathrm{Se}$

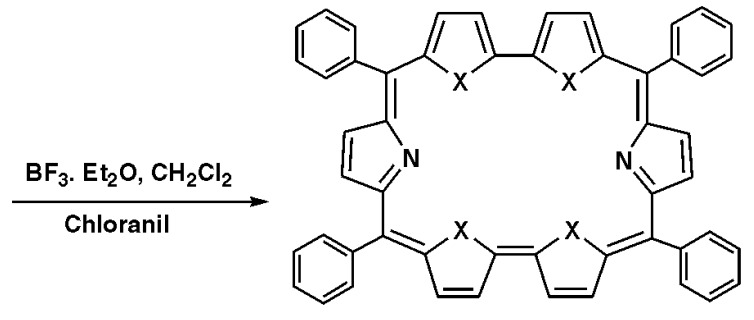

83

$\mathrm{X}=\mathrm{O}, \mathrm{S}, \mathrm{Se}$

Scheme 26.

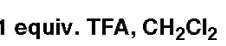

Chloran

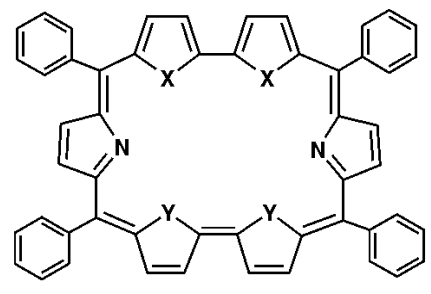

$85 Y=0, S$

$86 \mathrm{X}=\mathrm{S}, \mathrm{Se}$ 
7.1c Bronzaphyrin-[26] hexaphyrin-(2.0.0.2.0.0): This class of macrocycle owes its existence to the synthetic efforts of Johnson and Ibers ${ }^{20,21}$, Cava and coworkers ${ }^{83-85}$ and the groups of Merz and Neilden ${ }^{86}$. Heteroatom containing [26] hexaphyrin-(2.0.0.2.0.0), 76 was synthesized by a McMurry coupling involving monooxaterpyrrole or monothiaterpyrrole precursor 69 (scheme 29).

7.1d [26] Hexaphyrin-(1.1.1.1.0.0): Sessler and coworkers very recently reported an all-aza isomer of rubyrin with an inverted pyrrole ring $\mathbf{7 7}$, where the pyrrolic units are
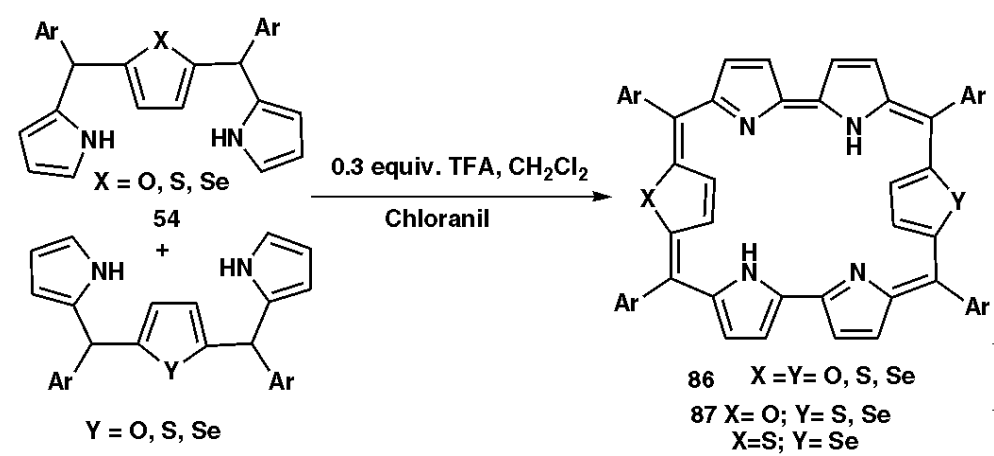

Scheme 27.

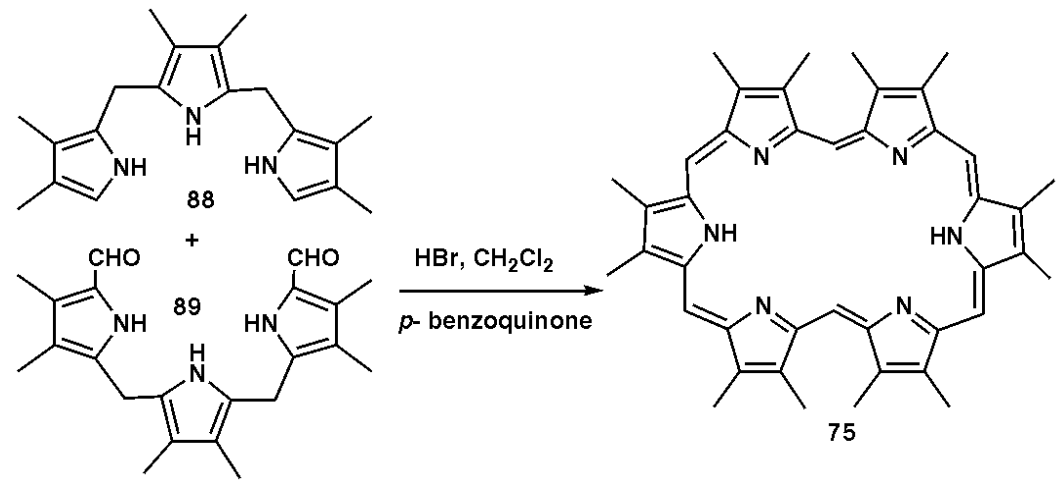

Scheme 28.

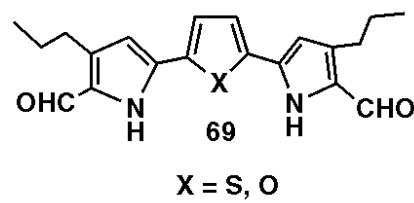

$\mathbf{X}=\mathbf{S}, \mathbf{O}$

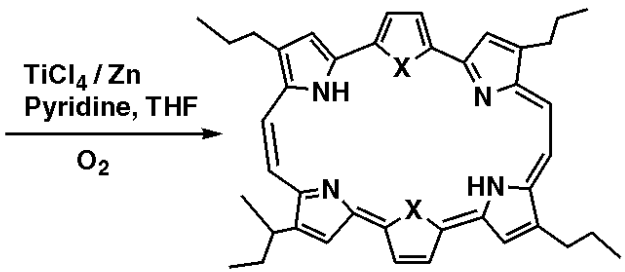

$76 \mathrm{X}=\mathrm{S}, \mathrm{O}$

Scheme 29. 
connected in a 1.1.1.1.0.0 fashion. This macrocycle was obtained in $46 \%$ yield from an acid-catalysed condensation reaction of a 1:1 mixture of diphenyltripyrrane $\mathbf{5 4}$ with the diformyl hexamethylterpyrrole $\mathbf{9 0}$ as shown in scheme $30^{87}$.

\subsection{Other aromatic systems}

Other aromatic hexaphyrinic systems reported are hexathia [34] hexaphyrin- (2.2.2.2.2.2) where each thiophene units are connected by two bridging carbon atoms ${ }^{7 b}$.

\subsection{Hexapyrrolic nonaromatic systems}

This class of hexaphyrins includes the conjugated but nonaromatic hexaphyrins reported so far. They are amethyrins, rosarins and other aromatic systems like hexaphyrins having 30 and $36 \pi$ electrons associated with them.

7.3a Amethyrin-[24] hexaphyrin-(1.0.0.1.0.0): Amethyrin $\mathbf{7 8}$ is the smallest hexapyrrolic macrocyclic system synthesized to date and it is a [24] hexaphyrin-(1.0.0.1.0.0). Sessler and coworkers were the first to report it in 1995 and the trivial name 'amethyrin' owes its origin to the amethyst colour of the parent material in dilute solutions ${ }^{13}$. It was synthesised from acid-catalysed condensation of terpyrrole $\mathbf{7 1}$ and formaldehyde followed by oxidation with DDQ or $p$-chloranil as shown in scheme 31 .

7.3b Rosarin-[24] hexaphyrin (1.0.1.0.1.0): Another nonaromatic hexapyrrolic macrocycle reported is [24] hexaphyrin-(1.0.1.0.1.0). It was assigned the trivial name 'rosarin' due to the pink-red colour it displays in its protonated form in organic solvents. Sessler and coworkers ${ }^{17}$ reported synthesising rosarin 79 via acid catalysed condensations involving bipyrrole $\mathbf{9 1}$ and aromatic aldehyde as shown in scheme 32.

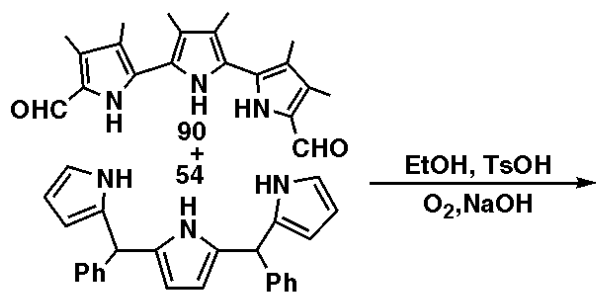

Scheme 30.

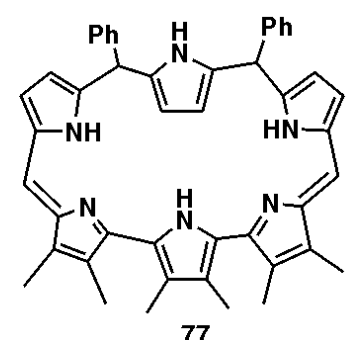

77<smiles>CC1=C(C)C(c2[nH]c(-c3[nH]cc(C)c3C)c(C)c2C)=NC1=Cc1[nH]c(-c2[nH]c(-c3[nH]c(-c4[nH]c(-c5[nH]cc(C)c5C)c(C)c4C)c(C)c3C)c(C)c2C)c(C)c1C</smiles>

Scheme 31 . 
7.3c [24] Hexaphyrin-(1.0.1.0.0.0): Sessler and coworkers have very recently reported [24] hexaphyrin- (1.0.1.0.0.0), 80 choosing appropriate hexapyrrolic precursors (scheme 33$)^{88}$. This is an isomer of amethyrin and is the smallest molecule containing a quarter pyrrole fragment.

\subsection{Other hexaphyrinoid systems}

Other nonaromatic hexapyrrolic macrocycles reported are hexathia [30] hexaphyrin(2.0.2.0.2.0) ${ }^{86}$, hexaoxa and hexathia [36] hexaphyrin-(2.2.2.2.2.2) by McMurry type reductive coupling of respective precursors ${ }^{77}$.

\subsection{Heptapyrrolic systems}

There are only very few reports on expanded porphyrins containing seven pyrrolic units till date. Seven pyrrolic units reported so far are shown in chart 3 . They can also be classified as nonaromatic and aromatic systems. Heptaphyrin $\mathbf{9 2}$ is nonaromatic ${ }^{22}$ while 93 and 94 are aromatic ${ }^{89}$.

\subsection{Higher order systems}

Larger macrocycles containing eight, ten, twelve and sixteen have been reported pyrrolic units. $2+2+2+2$-Condensation product of 1,2-(dipyrrolyl) ethane with a bipyrrole

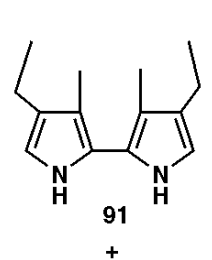<smiles>O=Cc1ccccc1</smiles>

Scheme 32.

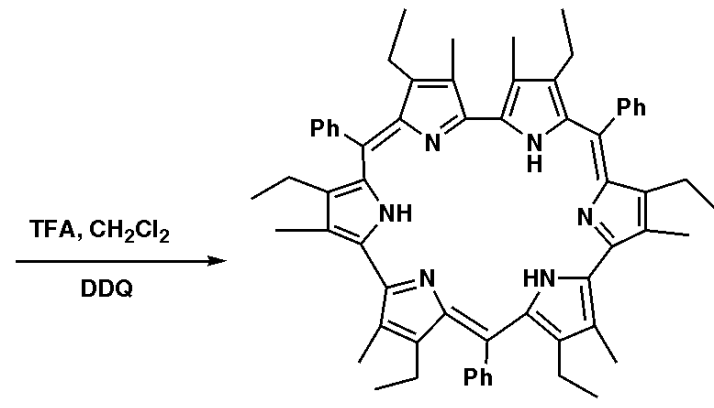

79

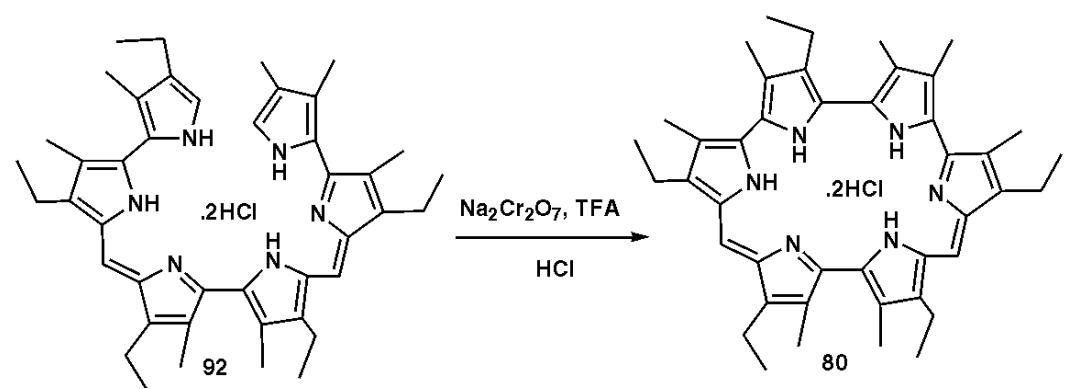

Scheme 33. 


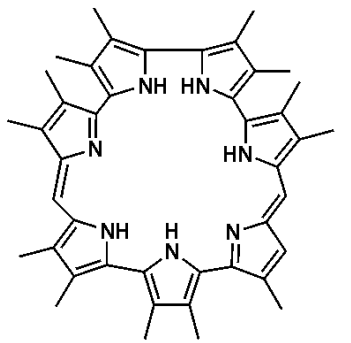

92: [28]heptaphyrin-(1.0.0.1.0.0.0)

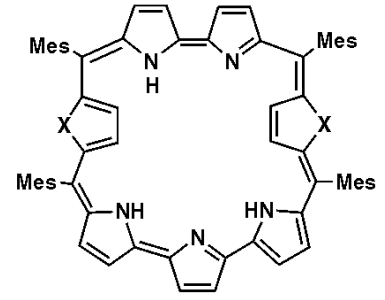

93: [30]heptaphyrin-(1.1.0.1.1.0.0) $\mathrm{X}=\mathrm{S}, \mathrm{Se}$

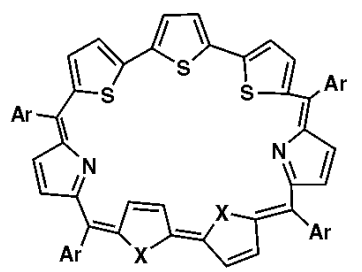

94: [30]heptaphyrin-(1.1.0.1.1.0.0), $\mathrm{X}=\mathrm{S}, \mathrm{Se}, \mathrm{O}$

Chart 3.

dialdehyde gave rise to the first octapyrrolic condensation product tetrahydrooctaphyrin(2.1.0.1.2.1.0.1), which on dehydrogenation afforded fully conjugated nonaromatic [36] octaphyrin-(2.1.0.1.2.1.0.1) $\quad \mathbf{9 5}^{14}$. Acid-catalysed condensation and subsequent dehydrogenation of tetraethyl substituted dipyromethane diacid with tetraethyl bipyrrole yielded a 2+2+2+2-product [34] octaphyrin-(1.1.1.0.1.1.1.0) $\mathbf{9 6}^{15}$. Another octapyrrolic system [32] octaphyrin-(1.0.1.0.1.0.1.0), 97 was synthesized from 4+4 condensation of tetrapyrrole with the related dialdehyde in presence of TFA ${ }^{15}$. All the octaphyrins 95-97 were reported by Vogel's group and they were found to exist in chiral figure eight conformations; the possibility exists that these might be separated into individual enantiomers. Compound 96 in spite of having $34 \pi$ aromatic pathways, revealed no

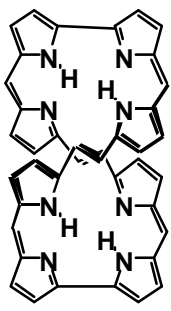

95

[36]Octaphyrin (2.1.0.1.2.1.0.1)

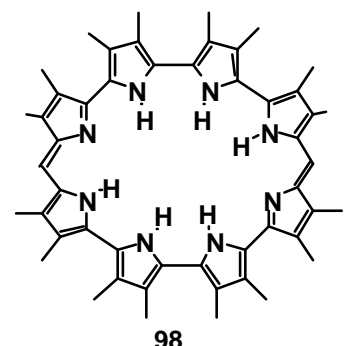

98

[32] octaphyrin

(1.0.0.0.1.0.0.0)

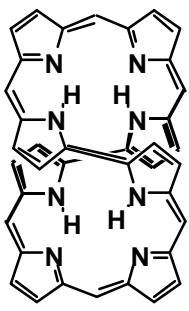

96 [34] Octaphyrin (1.1.1.0.1.1.1.0)

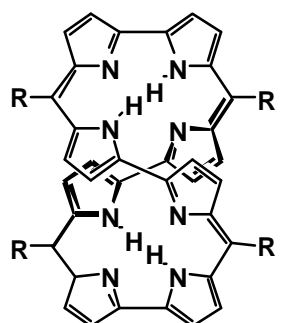

$97 \mathrm{R}=\mathrm{H}, \mathrm{Ar}$ [32] Octaphyrin (1.0.1.0.1.0.1.0)

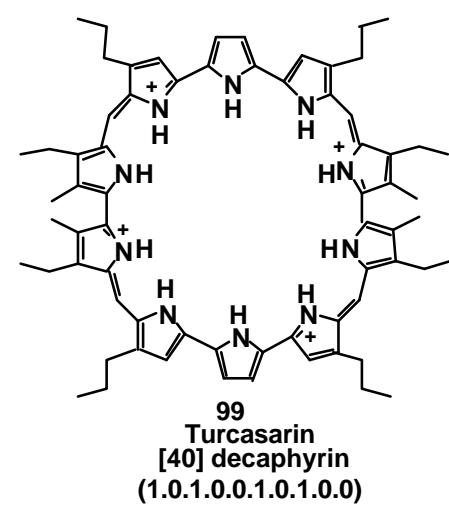


diamagnetic ring current and planarity associated with aromatic character in solution and solid state. This may be interpreted as the lack of overall aromaticity arising from nonplanarity, ring size and self-cancelling magnetic moments within each half of the macrocycle. Another [32] Joctaphyrin-(1.0.0.0.1.0.0.0) 98 was reported by Sessler et al by oxidative coupling of tetrapyrrole ${ }^{22}$. This compound was also nonaromatic and nonplanar but it does not take up a figure eight conformation unlike other octaphyrins reported. Another expanded porphyrin having ten pyrrolic units, turcasarin 99, named for its bright turquoise colour in organic solvent, was synthesized by Sessler and coworkers by cocondensation of terpyrrole and bipyrrole dialdehyde ${ }^{23} .98$ has $40 \pi$ electrons in its conjugative pathway and has the scientific name [40] decaphyrin (1.0.1.0.0.1.0.1.0.0). Setsune and coworkers reported an easy and efficient methodology for the syntheses of rosarin, octa, dodeca, and hexadecacyclopyrroles by utilising the age-old Rothemund synthetic procedure involving tetraethyl bipyrrole with benzaldehyde in presence of $0 \cdot 25$ eq. TFA followed by oxidation with DDQ. The macrocycles obtained were namely rosarin, [32] octaphyrin, [48] dodecaphyrin (1.0.1.0.1.0.1.0.1.0.1.0) $\mathbf{1 0 0}$ and [64] hexadecaphyrin (1.0.1.0.1.0.1.0.1.0.1.0.1.0.1.0) $\mathbf{1 0 1}^{24}$. Very recently Setsune et $a l^{90}$ have succeeded in synthesizing [80]icosapphyrin and [96]tetracosapphyrin.

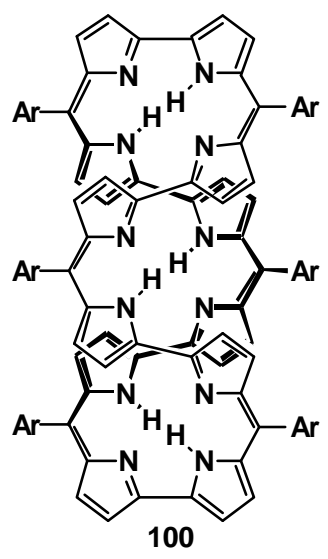

[48] dodecaphyrin$(1.0 .1 \cdot 0.1 \cdot 0.1 \cdot 0.1 \cdot 0.1 .0)$

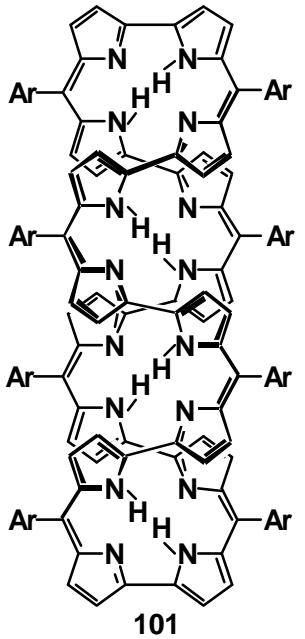

[64] hexadecaphyrin(1.0.1.0.1.0.1.0.1.0.1.0.1

\subsection{Aromatic $N$-confused sapphyrin}

Very recently Chandrashekar and coworkers ${ }^{91}$ have succeeded in synthesizing first example of modified sapphyrin with inverted $\mathrm{N}$-confused pyrrole ring (scheme 34 ). The single crystal structure of $\mathbf{1 0 5}$ shows inverted structure where the $\mathrm{N}$-confused pyrrole opposite the bithiophene unit is inverted and makes a dihedral angle of $25 \cdot 17^{\circ}$ with respect to the mean plane containing four meso carbons. The aromatic nature of $\mathbf{1 0 5}$ was evident from $C \alpha-C \beta$ being greater than $\mathrm{C} \alpha-\mathrm{C} \beta$ distances (1.46 vs 1.35 for one pyrrole ring). 


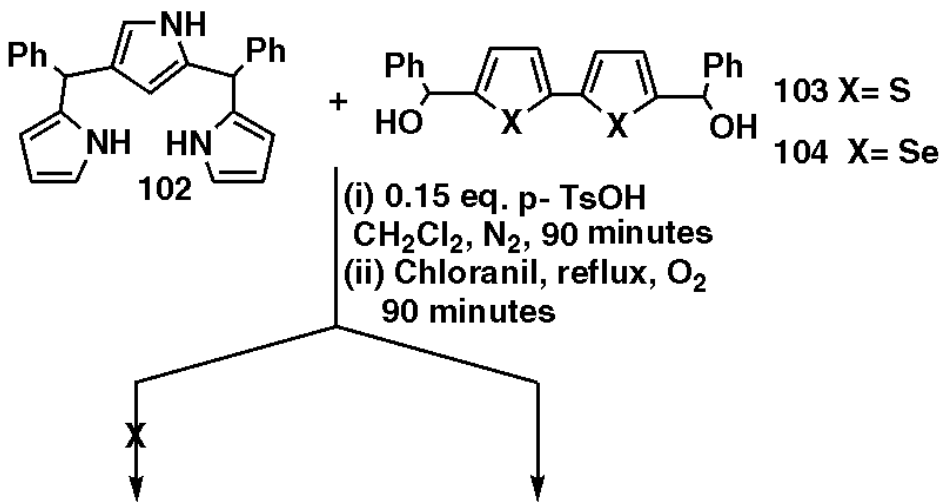

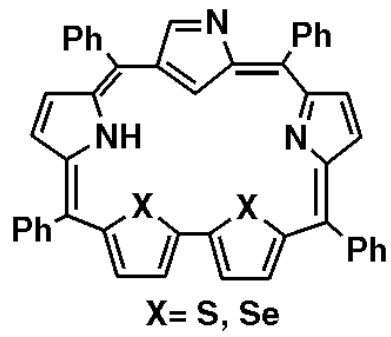<smiles>[Y][Y6](=O)[O-]</smiles>

Scheme 34.
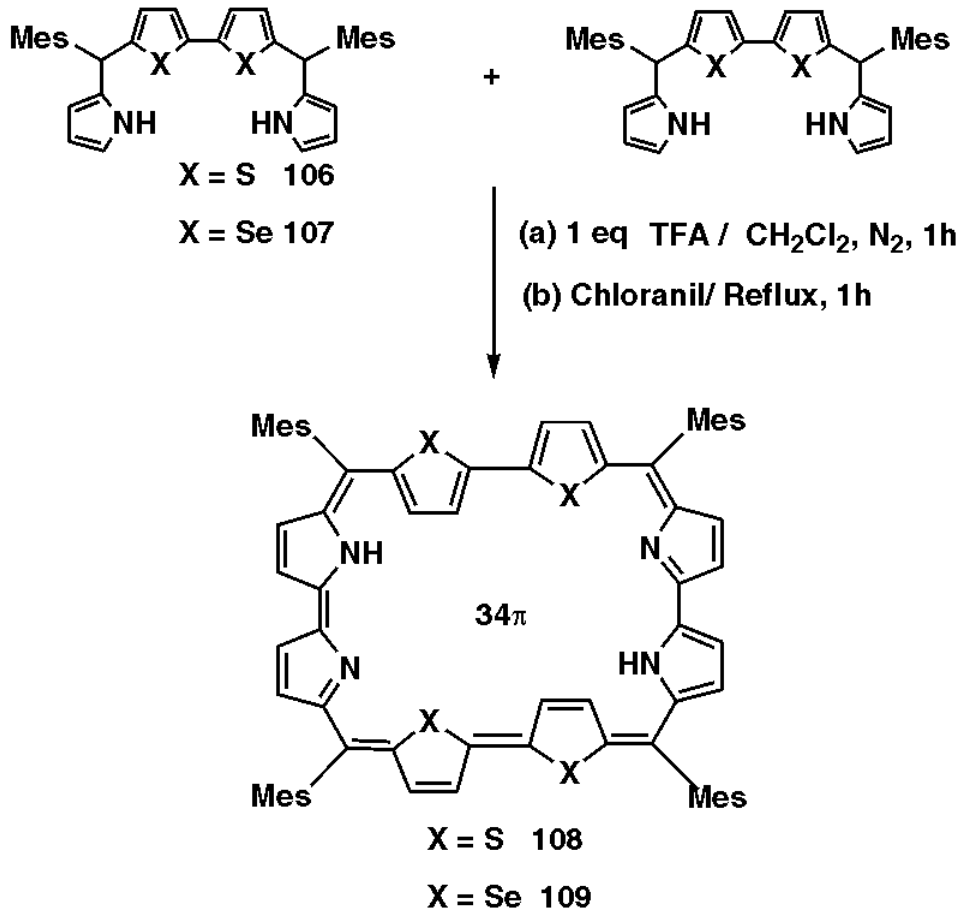

Scheme 35. 
Chandrashekar and coworkers ${ }^{92}$ reported the first example of aromatic $34 \pi$ modified octaphyrins through oxidative self coupling of 5,15-dimesityl-20,21-dithio-1-norbilane (scheme 35 ). The crystal structure of $\mathbf{1 0 8}$ indicates a completely planar structure, where one thiophene ring is inverted in each of the bithiophene units. The dihedral angle for the inverted thiophene with respect to the mean plane defined by four meso carbon atoms is $4.67^{\circ}$. The aromatic nature of the molecule is evident from the $\Delta \delta$ value $(17.32 \mathrm{ppm})$ and high $\varepsilon$ value $\left(\sim 10^{5}\right)$ for the Soret absorption in electronic absorption spectra.

\section{Acknowledgements}

We thank the Department of Science \& Technology and the Council of Scientific and Industrial Research, Government of India for the research grants provided.

\section{References}

1. Smith K M 1976 Porphyrins and metalloporphyrins (Amsterdam: Elsevier)

2. Dolphin D 1978 The porphyrins (New York: Academic Press) vol. 1-7

3. Battersby A R, Fookes C J R, Matcham G W J and McDonald E 1980 Nature(London) 17285

4. Latos-Grazynski L 2000 Core modified heteroanalogues of porphyrins. In The porphyrin handbook (eds) K M Kadish, K M Smith and R Guilard (New York: Academic Press)

5. Paolesse R 2000 Synthesis and application of corroles. In The porpyrin handbook (eds) KM Kadish, K M Smith and R Guilard (New York: Academic Press)

6. Sessler J L, Gebauer A and Vogel E 2000 Porphyrin isomers. In The porphyrin handbook (eds) K M Kadish, K M Smith and R Guilard (New York: Academic Press)

7. (a) Sessler J L and Weghorn S J 1997 Expanded, contracted and isomeric porphyrins (Oxford: Elsevier), and references therein; (b) Sessler J L, Gebauer A and Weghorn S J 2000 Expanded porphyrins. In The porphyrin handbook (eds) K M Kadish, K M Smith and R Guilard (New York: Academic Press)

8. Bauer V J, Clive D L J, Dolphin D, Paine J B, Harris F L, King M M., Loder J, Wand S W C and Woodward R B 1983 J. Am. Chem. Soc. 1056429

9. Broadhurst M J, Grigg R and Johnson A W 1972 J. Chem. Soc., Perkin Trans. 12111

10. Sessler J L, Davis J M and Lynch V 1998 J. Org. Chem. 637062

11. Rexhausen H and Gossauer A 1983 J. Chem. Soc., Chem. Commun. 275

12. (a) Gossauer A 1983 Bull. Soc. Chim. Belg. 92 793; (b) Gossauer A 1983 Chimia 37341

13. Sessler J L, Weghorn S J, Hiseada Y and Lynch V 1995 Chem. Eur. J. 156

14. Vogel E et al 1995 Angew. Chem., Int. Ed. Engl. 342511

15. Bröring M, Jendry J, Zander L, Schmickler H, Nendel M, Chen J, Plattner D A, Houk K N and Vogel E 1995 Angew. Chem., Int. Ed. Engl. 342515

16. Werner A, Michels M, Zander L, Lex J and Vogel E 1999 Angew. Chem., Int. Ed. Engl. 38 3650

17. Sessler J L, Weghorn S J, Morishima T, Rosingana M and Lynch V 1992 J.Am. Chem. Soc. 1148306

18. Sessler J L, Morishima T and Lynch V 1991 Angew. Chem., Int. Ed. Engl. 30977

19. Miller D C, Johnson M R, Becker J J and Ibers J A 1993 J. Heterocycl. Chem. 301485

20. Johnson M R, Miller D C, Bush K and Becker J J 1992 J. Org. Chem. 574414

21. Miller D C, Johnson M R and Ibers J A 1994 J. Org. Chem. 592877

22. Sessler J L, Seidel J and Lynch V 1999 J. Am. Chem. Soc. 12111257

23. Sessler J L, Seidel D, Lynch V and Johnson M R 1994 Angew. Chem., Int. Ed. Engl. 331509

24. Setsune J-I, Katakami Y and Iizuna N 1999 J. Am. Chem. Soc. 1218957

25. Henderson B and Dougherty T J 1992 Photodynamic therapy: Basic principles and clinical applications (New York: Marcel Dekker)

26. Sternberg E and Dolphin D 1996 Current Med. Chem. 3293

27. Dolphin D 1996 Can. J. Chem. 3293 
28. Lauffer R B 1987 Chem. Rev. 87901

29. Tweedle M F, Brittain H G, Eckelman W C, Gaughan G T, Hagan J J, Wedeking P W and Runge V M 1998 In Magnetic resonance imaging 2nd edn (ed.) C LW B Partain (Philadelphia: Sanders) vol. 1, p. 793

30. (a) Anderson S, Anderson H L and Sanders J K M 1993 Acc. Chem. Res. 26469; (b) Harriman A and Sauvage J-P 1996 Chem. Soc. Rev. 25 41; (c) Sauvage J-P 1998 Acc. Chem. Res. 31611

31. (a) Bonnet R 1995 Chem. Soc. Rev. 24 19; (b) Milgram L R and Mac Robert S 1998 Chem. Br. 3545

32. Fabian J, Nakazumi H and Matsuoka S 1992 Chem. Rev. 921197

33. (a) Ostovic D and Bruice T C 1992 Acc. Chem. Res. 25 314; (b) Meunier B 1992 Chem. Rev. 92 1411; (c) Dolphin D, Traylor T G and Xie L Y 1997 Acc. Chem. Res. 30251

34. Vogel E, Köchner M, Schmickler H and Lex J 1986 Angew. Chem., Int. Ed. Engl. 25257

35. (a) Sessler J L, Brucker E A, Weghorn S J, Kisters M, Schäfer M, Lex J and Vogel E 1994 Angew. Chem. Int. Ed. Engl. 33 2308; (b) Aukauloo M A and Guilard R 1994 New J. Chem. 18 1205

36. Callot H J, Rohrer A and Tschamber T 1995 New J. Chem. 19 155; (b) Vogel E et al 1997 Angew. Chem., Int. Ed. Engl. 361651

37. (a) Chemielewski P J, Latos-Grazynski L, Rachlewicz K and Glowiak T 1994 Angew. Chem., Int. Ed. Engl. 33 779; (b) Furuta H, Asano T and Ogawa T 1994 J. Am. Chem. Soc. 116767

38. (a) Vogel E 1996 J. Heterocycl. Chem. 33 1461; (b) Vogel E, Bröring M, Erben C, Demuth R, Lex J, Nendel M and Houk K N 1997 Angew. Chem., Int. Ed. Engl. 36353

39. Furuta H, Maeda H and Osuka A 2000 J. Am. Chem. Soc. 122803

40. Furuta H, Ishizuka T, Osuka A and Ogawa T 1999 J. Am. Chem. Soc. 1212045

41. Liu B Y, Bruckner C and Dolphin D 1996 Chem. Commun. 2141

42. Narayanan S J, Sridevi B, Srinivasan A, Chandrashekar T K and Roy R 1998 Tetrahedron Lett. 397389

43. (a) Geier G R III and Lindsey J S 1999 J. Org. Chem. 64 1596; (b) Geier G R III, Haynes D M and Lindsey J S 1999 Org. Lett. 11455

44. Lash T D, Richter T D and Shiner C M 1999 J. Org. Chem. 647973

45. (a) Szterenberg L and Latos-Grazynski L 1997 Inorg. Chem. 36 6287; (b) Chemielewski P J, Latos-Grazynski L and Glowiak T 1996 J. Am. Chem. Soc. 1185690

46. Chmielewski P J, Latos-Grazynski L and Schmidt I 2000 Inorg. Chem. 395475

47. Furuta H, Ogawa T, Uwatoko Y and Araki K 1999 Inorg. Chem. 382676

48. Furuta H, Kubo N, Ishizuka T, Osuka A, Nanami H and Ogawa T 2000 Inorg. Chem. 395424

49. Ogawa T, Furuta H, Takahashi M, Morino A and Uno H 2000 J. Organomet.Chem.611 551

50. Ghosh A 1995 Angew. Chem., Int. Ed. Engl. 1071117

51. Furuta H, Maeda H and Osuka A 2000 J. Org. Chem. 654222

52. Chmielewski P J and Latos-Grazynski L 1995 J. Chem. Soc., Perkin. Trans. 2503

53. (a) Heo P-Y, Shin K and Lee C-H 1996 Tetrahedron Lett. 37197 (b) Lee C-H and Kim H-J 1997 Tetrahedron Lett. 38 3935; (c) Heo P-Y, Shin K and Lee C-H 1996 Tetrahedron Lett. 37 1521; (d) Lee C-H, Kim H-J and Yoon D-W 1999 Bull. Korean Chem. Soc. 20276

54. Pacholska E, Latos-Grazynski L, Szterenberg L and Ciunik Z 2000 J. Org. Chem. 658188

55. Sprutta N and Latos-Grazynski L 1999 Tetrahedron Lett. 408457

56. Furuta H, Maeda H, Osuka A, Yasutaka M, Shinmyozu T and Ishikawa Y 2000 Chem. Commun. 1143

57. Woodward R B 1966 Aromaticity Conference, Sheffield, UK

58. Sessler J L, Johns on M R and Lynch V 1987 J. Org. Chem. 524394

59. Chmielewski P J, Latos-Grazynski L and Rachlewicz K 1995 Chem. Eur. J. 168

60. Bruckner C, Sternberg E D, Boyle R W and Dolphin D 1997 Chem. Commun. 1689

61. Paolesse R, Licoccia S, Spagnoli M, Boschi T, Khoury R G and Smith K M 1997 J. Org. Chem. 625133

62. Broadhurst M J, Grigg R and Johnson A W 1969 J. Chem. Soc., Chem. Commun. 23

63. (a) Sessler J L, Cyr M J and Burell A K 1991 Synlett. 127; (b) Sessler J L, Cyr M J and Burell A K 1992 Tetrahedron 48 9661; (c) Lisowski J, Sessler J L and Lynch V 1995 Inorg. Chem. 34 3567; (d) Rachlewicz K, Sprutta N, Chmielewski P J and Latos-Grazynski L 1998 J. Chem. Soc., Perkin Trans. 2 969; (e) Sessler J L, Hoehner M C, Gebaur A, Andrievsky A and Lynch V 1997 J. Org. Chem. 629251 
64. (a) Srinivasan A, Anand V G, Narayanan S J, Pushpan S K, Kumar M R, ChandrashekarT K, Sugiura K-I and Sakata Y 1999 J. Org. Chem. 64 8693; (b) Srinivasan A, Pushpan S K, Kumar M R, Mahajan S, Chandrashekar T K, Roy R and Ramamurthy P 1999 J. Chem. Soc., Perkin Trans. 2 961; (c) Srinivasan A, Mahajan S, Pushpan S K, Kumar MR and ChandrashekarT K 1998 Tetrahedron Lett. 391961

65. (a) Narayanan S J, Sridevi B, Chandrashekar T K, Vij A and Roy R 1998 Angew. Chem., Int. Ed. Engl. 37 3394; (b) Narayanan S J, Sridevi B, Chandrashekar T K, Vij A and Roy R 1999J. Am. Chem. Soc. 399053

66. Lash T D and Richter D T 1998 J. Am. Chem. Soc. 1209965

67. Gossauer A 1984 Chimia 3845

68. Vogel E 1996 J. Heterocyclic Chem. 331461

69. Vogel E, Pohl M, Hermann A, Wiss T, König C, Lex J, Gross M and Gisselbrecht J P1996 Angew. Chem., Int. Ed. Engl. 351520

70. Vogel E, Fröde C, Breihahn A, Schmickler H and Lex J 1997 Angew. Chem., Int. Ed. Engl.36 2609

71. Shin J-Y, Furuta H and Osuka A 2001 Angew. Chem., Int. Ed. Engl. 40619

72. Broadhurst M J, Grigg R and Johnson A W 1969 J. Chem. Soc., Chem. Commun. 1480

73. Narayanan S J, Sridevi B, Chandrashekar T K, Englich U and Senge K R 1999 Org. Lett.1 587

74. Weghorn S J, Lynch V and Sessler J L 1995 Tetrahedron Lett. 364713

75. Märkl G, Sauer H, Krietmeir P, Burgemeister T, Kastner F, Adolin G, Nöth H and Polborn K 1994 Angew. Chem., Int. Ed. Engl. 331151

76. Hu Z and Cava M P 1994 Tetrahedron Lett. 353493

77. Elix J A 1969 Aus. J. Chem. 221951

78. Knubel G and Franck B 1988 Angew. Chem., Int. Ed. Engl. 271170

79. Srinivasan A, Reddy V M, Narayanan S J, Sridevi B, Pushpan S K, Kumar M R and Chandrashekar T K 1997 Angew. Chem., Int. Ed. Engl. 362598

80. Srinivasan A, Pushpan S K, Kumar M R, Chandrashekar T K and Roy R 1999 Tetrahedron 6671

81. Narayanan S J, Srinivasan A, Sridevi B, Chandrashekar T K, Senge M O, Sugiura K-I and Sakata Y 2000 Eur. J. Org. Chem. 2357

82. Neves M G P M S, Martins R M, Tomé A C, Silverstre A J D, Silva A M S, Félix V, Drew M G B and Cavaleiro J A S 1999 Chem. Commun. 385

83. Hu Z, Atwood J L and Cava M P 1994 J. Org. Chem. 598071

84. Hu Z, Scordilis-Kelley C and Cava M P 1993 Tetrahedron Lett. 341879

85. Kozaki M, Parakka J P and Cava M P 1996 J. Org. Chem. 613657

86. Elinger F, Gieren A, Hübner T, Lex J, Merz A, Neildein R and Salbeck J 1993 Monatsch. Chem. 124931

87. Sessler J L, Seidel D, Bucher C and Lynch V 2000 Chem. Commun. 1473

88. Sessler J L, Seidel D, Vivian A E, Lynch V, Scott B L and Keogh D W 1994 Angew. Chem., Int. Ed. Engl. 331509

89. Anand V G, Pushpan S K, Srinivasan A, Narayanan S J, Sridevi B, Chandrashekar T K, Roy R and Joshi B S 2000 Org. Lett. 23829

90. Setsune J and Maeda S 2000 J. Am. Chem. Soc. 12212405

91. Pushpan S K, Srinivasan A, Anand V G, Venkatraman S, Chandrashekar T K, Joshi B S, Roy $\mathrm{R}$ and Furuta H $2001 \mathrm{~J}$. Am. Chem. Soc. 1235138

92. Anand V G, Pushpan S K, Venkatraman S, Dey A, Chandrashekar T K, Joshi B S, Roy R, Teng W and Senge K R $2001 \mathrm{~J}$. Am. Chem. Soc. 1238620 